\title{
Aerodynamic Design of Nozzles with Uniform Outflow for Hypervelocity Ground-Test Facilities
}

\author{
Wilson Y. K. Chan* , Peter A. Jacobs ${ }^{\dagger}$, Michael K. Smart ${ }^{\ddagger}$, Samuel Grieve ${ }^{\S}$, \\ The University of Queensland, Brisbane, QLD 4072, Australia
}

\author{
Christopher S. Craddock ${ }^{\mathbb{I I}}$ \\ Lloyd's Register, Southampton, UK \\ and Luke J. Doherty" \\ University of Oxford, UK
}

\begin{abstract}
A method is proposed for the aerodynamic design of nozzles with uniform outflow for supersonic and hypersonic ground-test facilities. This method involves the coupling of an open-source Reynolds-Averaged Navier-Stokes CFD solver, Eilmer, with the simplex optimisation method of Nelder \& Mead for the design of an expanding nozzle contour with the least variations in Mach number and flow angularity. Three nozzles were designed using this method to produce an exit flow of Mach 4, Mach 7 and Mach 10. Numerical simulations of the flow in these optimised nozzle contours showed excellent flow uniformity in the core flow - typical Mach number variations were less than $0.5 \%$, flow angularity variations were less than $\mathrm{0.05}^{\circ}$, static temperature and flow velocity variations were less than $1 \%$, and Pitot and static pressures variations were less than $2 \%$. Experimental surveys of the Pitot pressures at several planes downstream of the exit of the three optimised nozzles showed excellent agreement with numerical simulations. The experimental measurements showed that there were good levels of uniformity in the core flow regions of all three nozzles, thus proving the validity of the proposed design method.
\end{abstract}




\section{Introduction}

High-speed wind tunnel test facilities continue to contribute significantly to the advancement of science in the study of supersonic and hypersonic aerothermodynamics [1, 2, 3, 4]. These test facilities typically use converging-diverging Laval nozzles to generate supersonic and hypersonic test conditions. Up till the early 1990s, the design of these nozzles was based on the classical method proposed by Prandtl and Buseman [5] in 1929, commonly referred to as the MOC/BL technique [6]. The classical approach used the Method Of Characteristics (MOC) in an inverse design mode to determine an inviscid nozzle wall contour that produced the desired uniform exit flow. The contour would then be corrected with a displacement thickness obtained from a boundary-layer (BL) calculation to account for the boundary layer that developed along the nozzle wall.

The underlying assumption behind the MOC/BL method is that the boundary layer flow and mainstream flow are uncoupled. This is a reasonable assumption for geometrically-shorter low Mach number nozzles where boundary layers are thin, and the location where flow characteristics reflect is closely approximated by the inviscid contour. However, for longer high Mach number nozzles where boundary layers are thicker, the flow characteristics reflect in the region between the wall and the inviscid contour, as shown in Figure 1. This causes the actual reflected characteristic to lag the design reflected characteristic [7]. Nozzles designed using the classical MOC/BL method do not account for this shift in the reflection of the flow characteristics. This results in the incomplete cancellation of the expansion waves in the nozzle which then causes the nozzle outflow to be non-uniform. Hypersonic nozzles designed using the MOC/BL method for a Mach number of approximately 7, where turbulent boundary layers grow to a significant percentage of the exit radius, begin to show this effect [8].

To overcome this problem, Korte $[10,11,12]$ proposed a new design method that coupled a CFD solver with an optimisation algorithm to generate a nozzle contour which minimised the an-

\footnotetext{
*Postdoctoral Research Fellow, Centre for Hypersonics, School of Mechanical \& Mining Engineering, Member AIAA

${ }^{\dagger}$ Reader, Centre for Hypersonics, School of Mechanical \& Mining Engineering

¥Professor, Centre for Hypersonics, School of Mechanical \& Mining Engineering, Associate Fellow AIAA

${ }^{\S}$ T4 Shock Tunnel Engineer, Centre for Hypersonics, School of Mechanical \& Mining Engineering

"Manager, Technical Advisory \& Ship Performance

"Post-doctoral Research Assistant, Osney ThermoFluids Laboratory, Department of Engineering Science, Member AIAA
} 


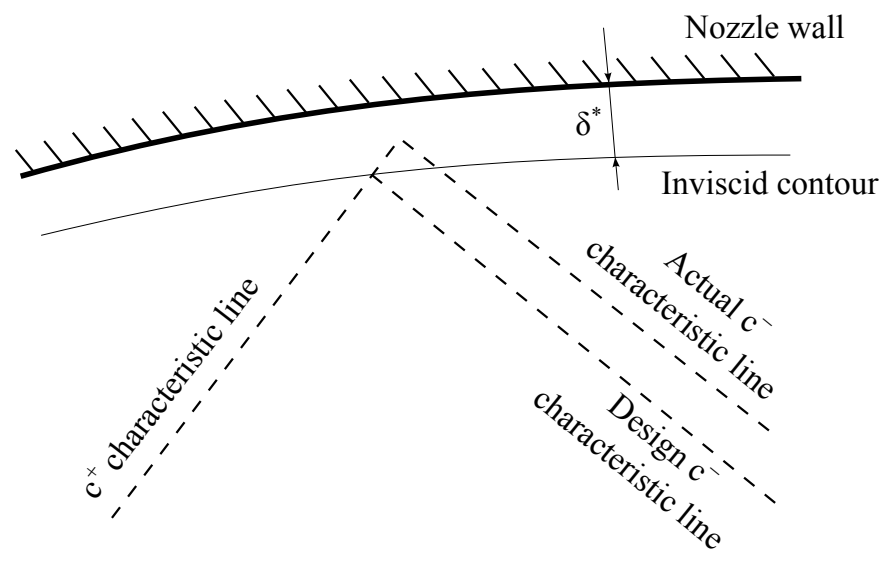

Figure 1. Lagging of actual characteristic from design characteristic due to reflection through a thick boundary layer (adapted from Reference [9]).

gularity and Mach number variation of the outflow. This method was also referred to by Shope [13] as the Design-By-Analysis (DBA) method. The primary advantage of Korte's method is that it uses Navier-Stokes equations based solvers which then offer the potential for the interaction between the core flow and the boundary layer in high Mach number nozzles to be correctly modelled. The flow solution and nozzle contour can then be forwarded to an optimization algorithm that iteratively perturbs the contour until a uniform nozzle exit flow is achieved. The accuracy of the design method is limited only by the accuracy of the flow solver used to perform the flowfield calculations and the ability of the optimiser to reach the desired optimum solution. In addition, this design method allows for the design of not only axisymmetric nozzles, but also three-dimensional nozzles by simply employing a three-dimensional flow solver. In Korte's work [10], a non-linear leastsquares optimization procedure was coupled with a parabolised Navier-Stokes CFD flow solver for the optimisation of the exit flow profile of a MOC/BL-designed nozzle. Since then, several other authors $[13,14,15]$ have applied variants of Korte's work to the design of hypersonic nozzles. It is good to note that Korte's design approach theoretically allows any combination of CFD solvers and optimisation algorithms to be used in the design process.

This paper presents another variant of Korte's work. Rather than coupling a parabolised NavierStokes CFD solver with the least-squares optimiser, an open-source Reynolds-Averaged Navier- 
Stokes CFD solver, Eilmer [16], was coupled with the simplex optimisation method of Nelder \& Mead [17] for the design of a nozzle contour which produces an outflow with the least flow angularity and the least deviations from the desired Mach number. This paper starts with a description of the design methodology, followed by details of the application of the method for the design of three nozzles for a free-piston shock tunnel test facility - a Mach 4, Mach 7 and Mach 10 nozzle. Finally, results from experimental surveys of the outflow of the three nozzles designed using this method are shown as validation of the appropriateness and robustness of the proposed design methodology.

\section{Design methodology}

The design method proposed in the current paper couples a Reynolds-Averaged Navier-Stokes CFD solver, Eilmer [16], with the simplex optimisation method of Nelder \& Mead [17] for the design of a nozzle contour which produces an outflow with the least flow angularity and the least deviations from the desired Mach number. The optimisation problem was formulated using (1) seven geometrical design variables that defined the shape of the expansion contour, and (2) an objective function that defined the deviations in Mach number and flow angularity from prescribed goals across the test core at the exit plane of the nozzle. Values for the seven geometrical design variables were then adjusted to minimise the objective function.

The CFD flow solver, Eilmer, is an integrated collection of programs that solves the compressible Navier-Stokes equations in multi-block structured grids to provide time-accurate simulations of two and three-dimensional compressible flows. It was selected as the flow solver for the current design method because it has been validated for use on many supersonic/hypersonic test cases $[18,19,20,21,22,23,24]$, and because it can be used to model high-speed flows in chemical and thermal equilibrium and non-equilibrium. To streamline the process of running multiple nozzle CFD simulations, a set of scripts (called NENZFr [25] which stands for Non-Equilibrium NozZle Flow - Reloaded) was written to coordinate repeated runs of a pseudo-space-marched nozzle simulation using Eilmer. Our pseudo-space-marching approach was used to accelerate a calculation which has a predominant flow direction and little feedback. Space-marching is not new 
but it is interesting to show that, with a modern scripting language (Python), it is easy to retrofit the space-marching capability to a standard time-marching CFD solver.

For the optimiser in the current design method, the gradient-search algorithm of Nelder \& Mead [17] was chosen for its robustness and ease of implementation. Since the Nelder \& Mead optimiser suffers from the same flaw as all gradient-search optimisers (in that it finds only the local optimum solution), it is essential that the nozzle contour used to initialise the calculations in the current design method produces an outflow that does not deviate significantly from target outflow conditions.

\section{A. Initialising the optimisation problem}

The design method starts with the definition of an initial nozzle contour. While initialising the optimisation problem with a nozzle contour which has been generated using the MOC/BL method is a robust approach, another method of generating an initial contour is to scale an existing nozzle contour (designed for approximately the same exit Mach number) to reflect the required area ratio, nozzle length and nozzle-exit diameter of the new nozzle.

The initial nozzle contour is defined a single continuous Bèzier curve. For the present study, nine Bèzier control points were used, as shown in Figure 2. The radial positions of the first two control points were held constant at the nozzle throat radius, $r_{\text {throat }}$ and the radial positions of the remaining seven control points were free to move. For this design method, the axial positions of all control points were fixed and their distribution along the length of the nozzle was slightly clustered towards the nozzle throat. This clustering was done because the largest amount of change in the contour (curvature) was expected just downstream of the nozzle throat region. The differences in radial distances between each pair of Bèzier control points that were free to move $\left(Y_{1}-r_{\text {throat }}\right.$, $\left.Y_{2}-Y_{1}, \ldots ., Y_{7}-Y_{6}\right)$ were used as design variables for the optimisation problem. In contrast

to using $Y_{i}$ directly as design variables, this approach makes the design variables resemble wall slopes and helps to improve the convergence of the design procedure [11].

Note that the radial positions of the first two Bèzier control points were held constant to ensure that the optimised contour always started parallel to the axis of the nozzle. While it was not 


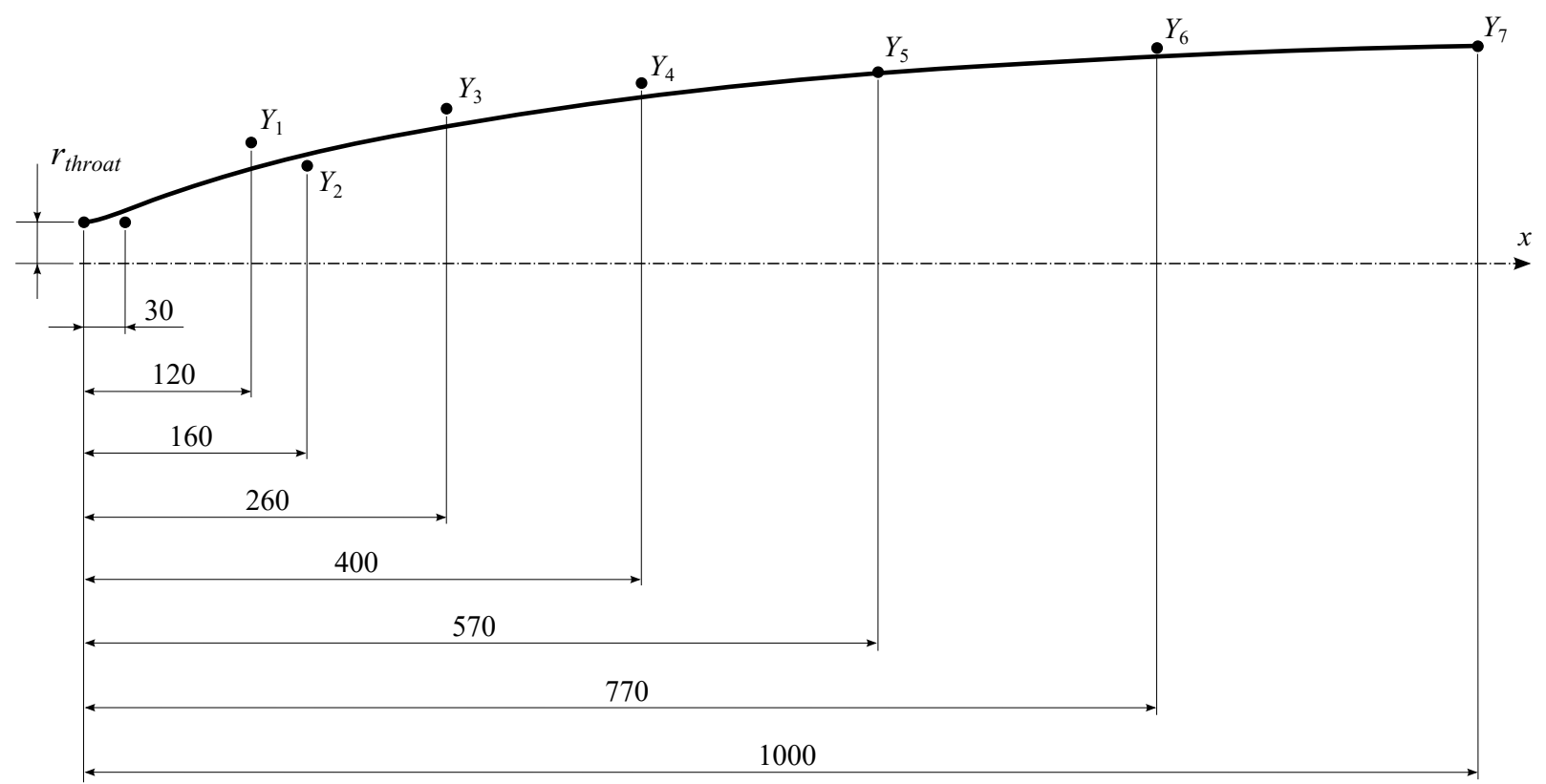

Figure 2. Layout of the Bèzier control points that define the nozzle contour.

attempted in this study, perhaps the radial positions of the last two Bèzier control points should also be held constant to ensure that the very last millimetres of the contour always came in parallel to the axis at the exit of the nozzle.

\section{B. Defining the objective function of the optimisation problem}

The objective function was defined so that the optimization algorithm would attempt to find a nozzle shape that produced a flow with a minimum of variation in Mach number and flow angle across the core flow at the nozzle-exit plane. Note that this design method is not limited to target for an optimum Mach number and flow angle; the nozzle contour can also be optimised for other flow parameters (for example, static pressure, temperature and velocity). All computational cells from the nozzle axis to the edge of the core flow ${ }^{\mathrm{a}}$ at the exit plane were used to evaluate the objective function which was defined as,

$$
\lambda=\left(f_{\theta}+f_{M}\right)^{2}
$$

\footnotetext{
${ }^{a}$ The edge of the core flow was defined as the radial position on the outflow plane where the gradient $\partial M / \partial r$ became less than -20.0 along a radial line moving away from the axis.
} 
where $f_{\theta}$ and $f_{M}$ define the variation in flow angle, $\theta$, and the distribution in Mach number, $M . f_{\theta}$ and $f_{M}$ are given by

$$
\begin{gathered}
f_{\theta}=\frac{\phi_{\theta}^{2}}{N} \sum_{j=1}^{N}\left(v_{j} / u_{j}\right)^{2} \\
f_{M}=\frac{\phi_{M}^{2}}{N} \sum_{j=1}^{N}\left(M_{x, j}-M_{\text {design }}\right)^{2}
\end{gathered}
$$

where the symbol $N$ denotes the number of cells in the core flow. Two weighting parameters, $\phi_{\theta}$ and $\phi_{M}$, were used to scale the contributions of the flow angle variation function $f_{\theta}$ and Mach number variation function $f_{M}$. The scaling parameters were set so that both functions would evaluate to 1 or less if all of the cells within the core flow have a variation in Mach number and flow angle less than a prescribed target.

Note that the optimisation method used here searches for the minimum (optimum) of a single objective function which has been lumped together from two weighted objective parameters the Mach number and the flow divergence. This is commonly known as a single-objective optimisation, and is useful when the nozzle designer knows how to weight each objective parameter. Should the designer have no knowledge on what weighting to apply to each objective parameter, then perhaps a multi-objective optimisation approach can be taken. While the multi-objective ap-

proach provides no single optimal solution, its advantage lies in that the method provides a set of alternative solutions which trade different objectives against each other. These solutions can then allow nozzle designers to decide themselves which is the optimal solution for their application.

\section{Application of method to the design of a Mach 7 nozzle}

The design methodology was applied to the design of three axisymmetric contoured nozzles for the T4 free-piston shock tunnel - a high-enthalpy hypersonic test facility [3]. The three nozzles were designed to generate exit Mach numbers of 4, 7 and 10. For conciseness, only details for the application of this design method for the Mach 7 nozzle are shown in this paper. 


\section{A. Design constraints}

The Mach 7 nozzle was designed to generate an exit flow with a Mach number that varies by less than 0.01 of 7 , and with a flow angularity that varies by less than $0.02^{\circ}$. This nozzle was to be supplied with stagnated air in chemical equilibrium at a nozzle-supply pressure $p_{s}$ of $8.32 \mathrm{MPa}$ and a nozzle-supply temperature $T_{s}$ of $2122.7 \mathrm{~K}$ (which corresponded to a nozzle-supply enthalpy of $2.44 \mathrm{MJ} / \mathrm{kg}$ ). Note that while the order of the variations in the target conditions cannot be easily measured in pulse-flow wind tunnels with the current generation of flow measurement instruments, these design targets were deliberately set to strict "ideal" levels to improve the convergence of the optimisation search algorithm.

From these targets, the weighting parameters $\phi_{\theta}$ and $\phi_{M}$ were then calculated to be equal to the inverse of the targets, such that

$$
\begin{gathered}
\phi_{\theta}=\frac{1}{\tan (0.02)}=2.86 \times 10^{3} \\
\phi_{M}=\frac{1}{0.01}=100
\end{gathered}
$$

For the current study, the flow simulations were performed from the start of the sonic throat of the nozzle rather than the nozzle-supply region to help simplify the calculations ${ }^{\mathrm{b}}$. The flow conditions at the throat of the nozzle were computed by assuming a hypothetical isentropic expansion (occurring in thermal and chemical equilibrium) from the nominally-stagnant nozzle-supply region. The flow in the throat region was computed to have a flow velocity $u_{\text {throat }}$ of $828.8 \mathrm{~m} / \mathrm{s}$, static pressure $p_{\text {throat }}$ of $4.55 \mathrm{MPa}$ and static temperature $T_{\text {throat }}$ of $1861.7 \mathrm{~K}$. Figure 3 shows profiles of Mach number and flow divergence at the exit of the nozzle for a simulation started at the sonic throat of the nozzle (i.e. modelled without the nozzle-supply region), and the other modelled with the nozzle-supply region. As shown, the nozzle-exit profiles are extremely similar; the maximum difference in the Mach number and flow divergence is $<0.1 \%$ and $<0.2^{\circ}$ respectively. This result shows that it is reasonable to start the flow simulations from the throat of the nozzle.

\footnotetext{
${ }^{b}$ Note though that the proposed design method does not restrict where the flow simulations are started.
} 


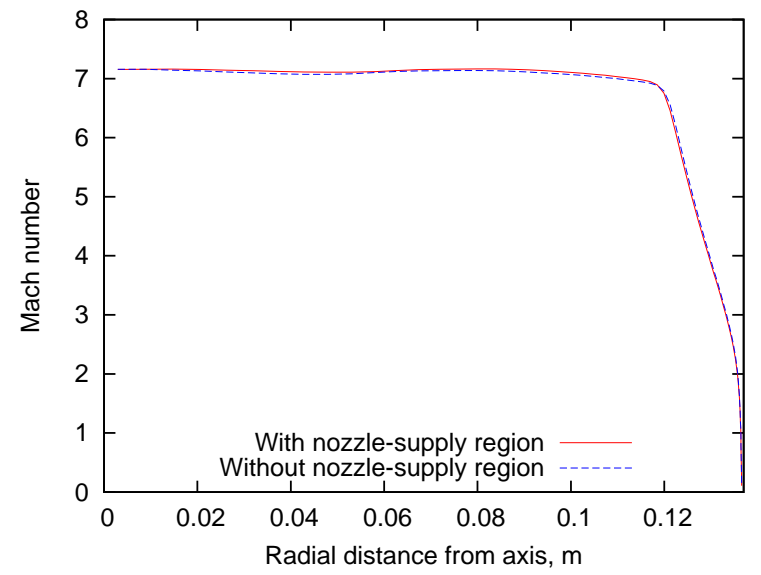

a) Mach number.

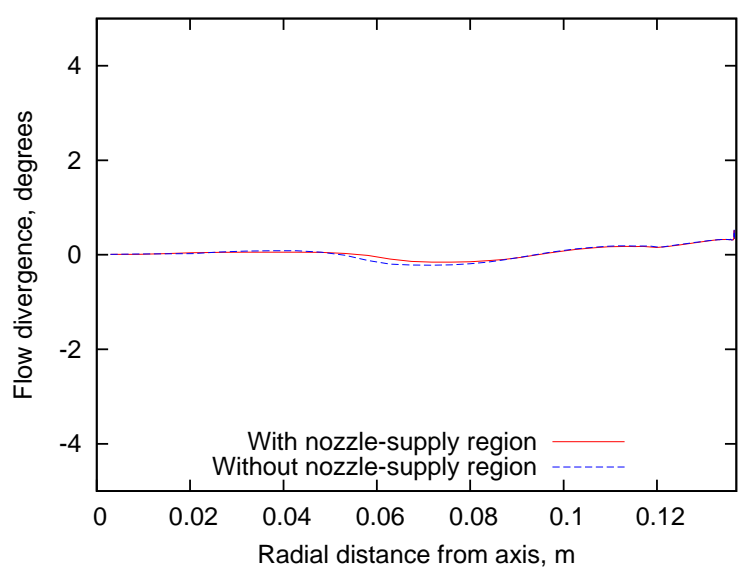

b) Flow angularity.

Figure 3. Effect of modelling the nozzle-supply region on the Mach number and flow divergence at the exit of the nozzle.

In addition to the target flow conditions, there were also constraints on the physical size of the nozzle, due to the facility that it was designed for. For this nozzle, the diameter of the nozzle throat was constrained to $21 \mathrm{~mm}$, and the axial length of the nozzle from throat to nozzle-exit was constrained to $1 \mathrm{~m}$. Note that the nozzle-exit diameter was not constrained.

\section{B. Setup parameters for flow simulations and for the optimiser}

The computational grid for the flow simulations had 300 cells in the axial direction and 40 cells in the radial direction. As shown in Figure 4, grid clustering was employed near the throat and initial expansion regions to resolve the larger flow gradients expected in these regions. Grid clustering was also employed near the nozzle wall to ensure sufficient resolution of the boundary layer. In addition, the grids near the nozzle wall were configured to be orthogonal to the wall to ensure that the near-wall flow parameters were properly approximated by the flow solver. The wall of the nozzle was assumed to be at a constant temperature of $300 \mathrm{~K}$ - a valid assumption for impulse facilities where short test times (in the order of milliseconds) restrict the increase in wall temperatures to only several Kelvins. The $y^{+}$values of most near-wall cells were under 1.0.

The conditions for the sonic inflow of air through the throat of the nozzle were as stated in Section A. Given the low value of nozzle-supply enthalpy of $2.44 \mathrm{MJ} / \mathrm{kg}$ for the design condi- 


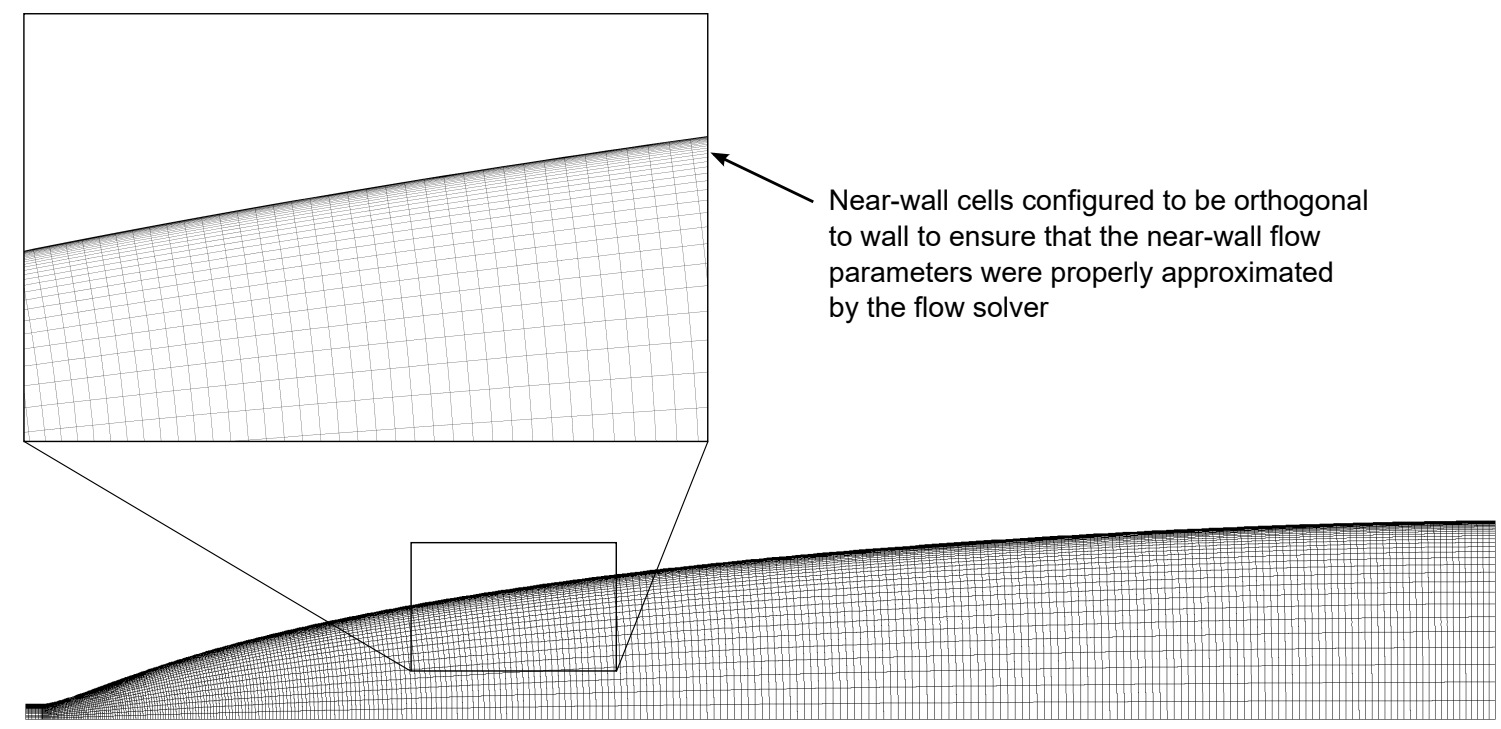

Figure 4. Computational grid for each NENZFr simulation.

tions, the flow of air through the nozzle was assumed to be in thermal and chemical equilibrium. A flow simulation conducted with a similar setup but with finite-rate chemistry with the Gupta 5-species model for air [26] showed similar results to that conducted with chemical equilibrium. Also, Hannemann et. al. [27] showed in their nozzle flow simulations that for low enthalpy flows of approximately $3.3 \mathrm{MJ} / \mathrm{kg}$, the flow in the nozzle was better modelled assuming thermal equilibrium. In addition, the flow domain was initialised with the same flow and gas conditions as those used in the inflow boundary.

The turbulence model used in the simulations was Wilcox's $2006 k$ - $\omega$ turbulence model [28]. The turbulence intensity of the inflow to the nozzle is set to $5 \%$ and the ratio of turbulent-to-laminar viscosity of the inflow to the nozzle is set to 100 . Turbulence was assumed to start at the throat of the nozzle. Simulations with turbulence starting at between $0-150 \mathrm{~mm}$ from the throat showed that varying the transition location did not significantly affect the flow conditions at the exit plane of the nozzle. For boundary layer transition locations up to $150 \mathrm{~mm}$ from the throat, the maximum deviation from that when boundary layer transitioning occurs at the throat is $+0.2 \%$ for nozzle-exit velocity, $+1.5 \%$ for nozzle-exit Mach number, $-3 \%$ for nozzle-exit static temperature, $-5 \%$ for 
nozzle-exit Pitot pressure and nozzle-exit static density, and $-8 \%$ for nozzle-exit static pressure.

The optimisation algorithm of Nelder \& Mead required values for the initial perturbations of the design variables to allow the initial parameter space to be set. These values were chosen to be $3 \mathrm{~mm}$ for the first two upstream design variables and $5 \mathrm{~mm}$ for the remaining five design variables. Other parameters used for the Nelder \& Mead algorithm can be found in the report by Chan et. al. [29]. For the Mach 7 nozzle, the initial contour was scaled from an existing Mach 7.6 nozzle contour [9] of approximately the same physical size.

\section{Optimisation results for the Mach 7 nozzle}

The optimisation run converged at 115 iterations (totalling 383 NENZFr simulations) with a value for the objective function of 2.9. As mentioned before in Section A, the target objective function value of 1 was set to improve the convergence of the optimisation algorithm, and can only be achieved for an ideal case. It is hence not surprising that the converged objective function value for the present optimisation run did not reach the target objective value of 1 . The 383 NENZFr flow simulations took approximately 64 hours to complete when run parallel on 8 Intel L5520 $2.27 \mathrm{GHz}$ processors.

Figure 5 shows the optimised nozzle contour in relation to the initial un-optimised contour. The optimised nozzle contour had a nozzle-exit diameter of $273.2 \mathrm{~mm}$. The maximum slope of the optimised nozzle contour (relative to the nozzle axis) was $20^{\circ}$ and occurred approximately $42 \mathrm{~mm}$ downstream of the nozzle throat.

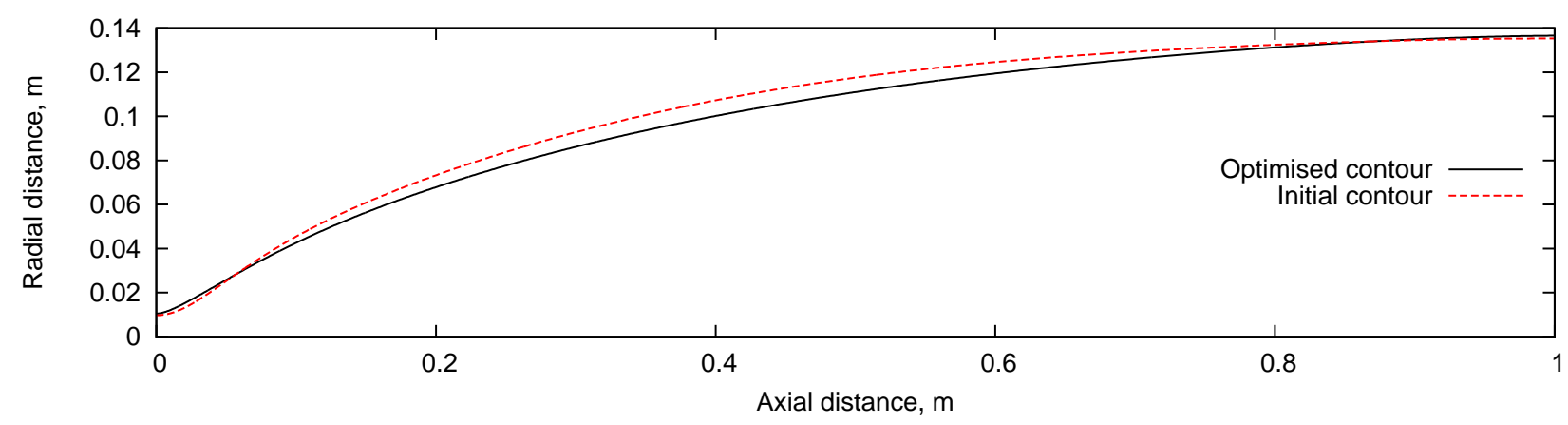

Figure 5. Optimised contour for the Mach 7 nozzle in relation to the initial contour used for the optimisation. 
Radial distributions of Mach number, flow angularity, static pressure and Pitot pressure across the nozzle-exit plane for the optimised nozzle contour are shown in Figure 6. Flow profiles from two other simulations with different grid densities are also shown in Figure 6. The coarse grid, which was the grid used for the optimisation run, has 40 radial cells and 300 axial cells. The medium grid has 80 radial cells and 600 axial cells. The fine grid has 120 radial cells and 900 axial cells. Although another simulation with a coarser grid of 20 radial cells and 150 axial cells was conducted, it has been omitted from Figure 6 so as to improve clarity in the plots. Note that the Pitot pressures in Figure 6d were calculated using the Rayleigh-Pitot equation with the assumption of a constant ratio of specific heats of 1.4. For the present case, the total enthalpy is sufficiently low that the Pitot pressure calculated using the Rayleigh-Pitot equation differs from that calculated assuming real gas effects by only $1 \%$.

These profiles show that the medium grid produced a flowfield at the exit of the nozzle that was sufficiently grid-converged for the analysis conducted in the present study; the average Mach number, flow angularity and Pitot pressure within the core flow for the medium grid were less than $1 \%$ different from those for the fine grid, while the average static pressure was $1.3 \%$ different. To further show the level of grid convergence, a plot of the total axial force acting on the nozzle is plotted against the total number of cells for each grid resolution in Figure 7. The total axial force was calculated by integrating the surface pressure and viscous stress acting on the nozzle wall from the throat to the exit plane of the nozzle. Although the force acting on the nozzle is not a particularly relevant property for the current study, it is more sensitive to the flow solution than the objective function [30]. Figure 7 shows that the calculated total axial force converges to a value of approximately $1.87 \mathrm{kN}$ as the normalised grid spacing decreases towards zero - this is a good indication of grid convergence. Using the generalised version of Richardson extrapolation [31], the errors in calculated axial force for the three highest resolution grids are $4.0 \%, 3.4 \%$ and $2.1 \%$.

Also shown in Figure 6 are the exit flow data for an equivalent nozzle designed via the classical method of characteristics with added boundary-layer correction (MOC/BL) [6, 8]. The inviscid profile determined via the MOC calculation had an exit diameter of $248 \mathrm{~mm}$ and the displacement thickness added to that profile reached a maximum value of $6 \mathrm{~mm}$ at the exit plane. While the dis- 


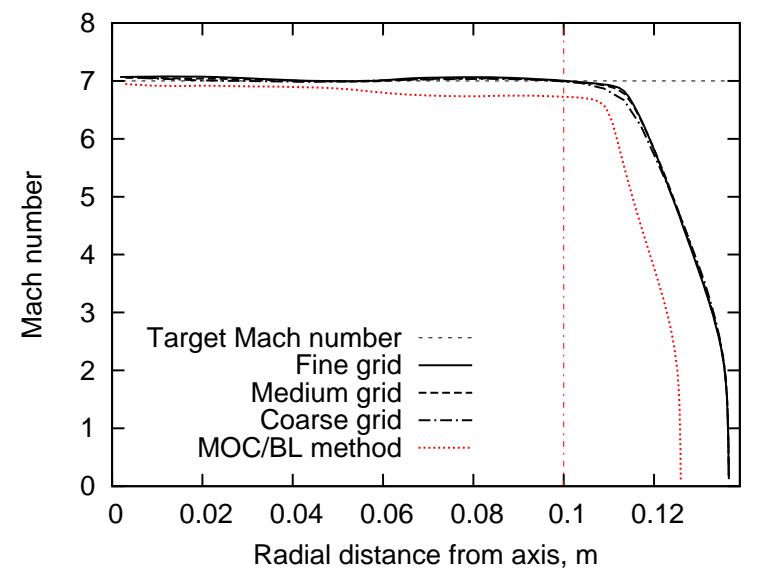

a) Mach number.

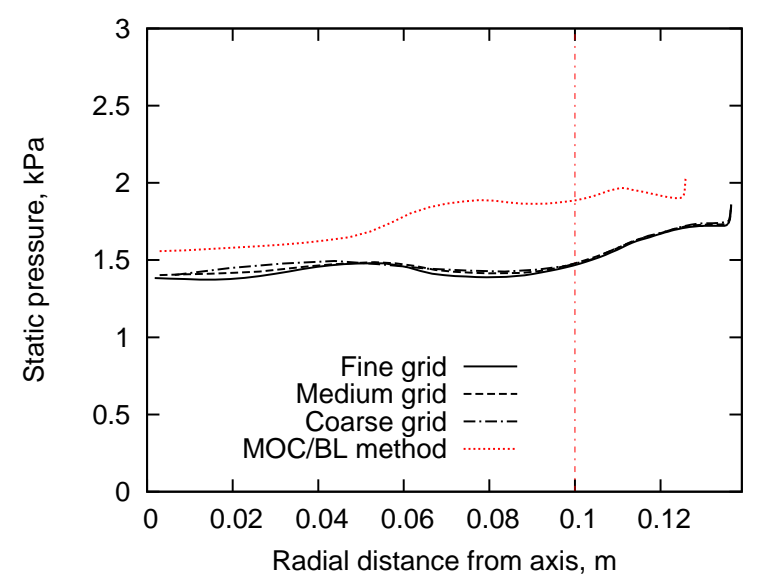

c) Static pressure.

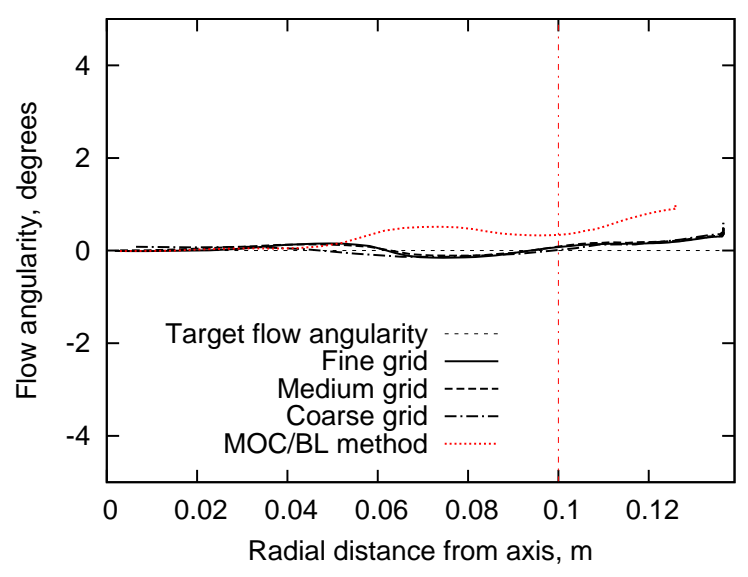

b) Flow angularity.

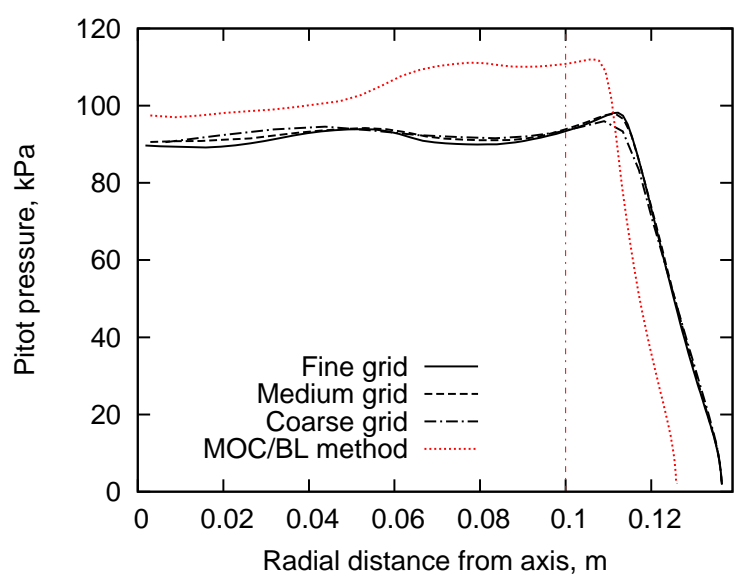

d) Pitot pressure.

Figure 6. Flow profiles at the exit of the nozzle designed using the current method for three grids. Also shown are profiles from a nozzle contour designed using the MOC/BL method. Note that the vertical line at the radial distance of $0.1 \mathrm{~m}$ indicates the radial size of the core flow. 


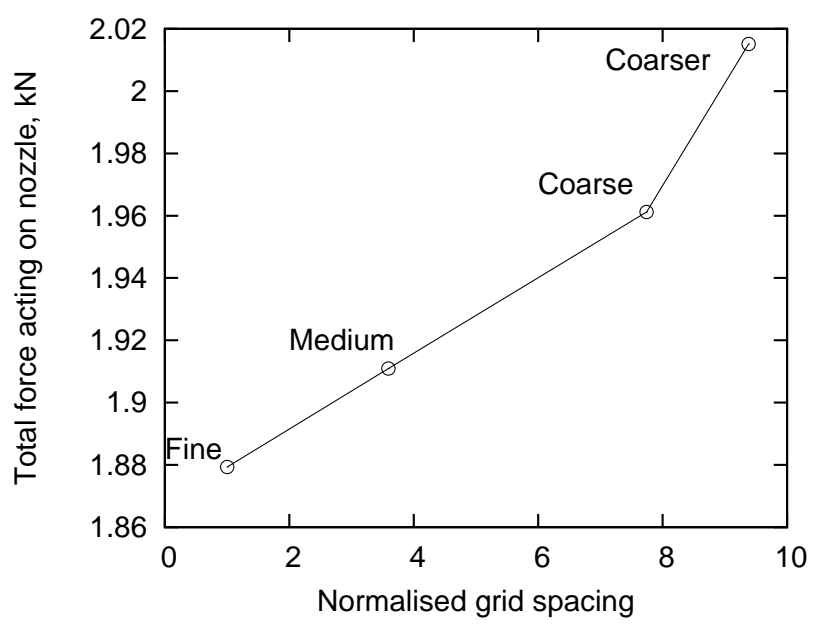

Figure 7. Grid convergence analysis based on total force acting on nozzle.

placement thickness correction applied is not on the same order of magnitude as the exit diameter of the nozzle, it is still sufficiently large that correcting the inviscid nozzle profile without proper consideration of the wave processes will produce a final wall profile with poorer performance [8]. In comparison with the exit flow profiles of the nozzle designed using the proposed method, it is evident that the quality of the nozzle-exit flow of the MOC/BL nozzle contour is poorer.

The plots in Figure 6 show that, for all grid configurations, the maximum test core diameter at the nozzle-exit plane was approximately $200 \mathrm{~mm}$. Mass-flow-weighted averaged values of flow properties in the test core for the medium grid are summarised in Table 1. To demonstrate the uniformity of the nozzle-exit flow, values for the maximum deviation from the mass-flow-weighted averaged flow properties in the test core are also included in Table 1 . Other than the $\pm 3 \%$ deviation in static pressure and $\pm 2 \%$ deviation in Pitot pressure, the other flow parameters had deviations of less than $\pm 1 \%$ in the test core at the nozzle-exit plane. This thus shows that the flow within the test core is sufficiently uniform. In addition, a comparison with target conditions is also provided in Table 1. The results demonstrate that the optimisation process produced a nozzle-exit Mach number of within 0.02 of the target of 7.0 and a flow divergence of within $0.006^{\circ}$ of the target of $0^{\circ}$.

Another parameter of interest is the size of the test core that the optimised nozzle contour provides. Figure 8 shows plots of Pitot pressure contours that were generated from simulations of 
Table 1. Mass-flow-weighted averaged values (with their respective maximum deviations) of flow properties in the uniform test core.

\begin{tabular}{ccccccc}
\hline \hline Flow & Units & $\begin{array}{c}\text { Mass-flow } \\
\text {-weighted } \\
\text { value }\end{array}$ & $\begin{array}{c}\text { Maximum } \\
\text { deviation } \\
\text { parameter }\end{array}$ & $\begin{array}{c}\text { Maximum } \\
\text { deviation } \\
\text { (relative) }\end{array}$ & $\begin{array}{c}\text { Target } \\
\text { Value }\end{array}$ & $\begin{array}{c}\text { Deviation } \\
\text { from target }\end{array}$ \\
vach number & - & 7.0215 & \pm 0.03 & $\pm 0.4 \%$ & 7.0 & 0.0215 \\
Flow divergence & $\circ$ & 0.006 & \pm 0.13 & - & 0.0 & 0.006 \\
Static pressure & $\mathrm{kPa}$ & 1.4435 & \pm 0.041 & $\pm 2.8 \%$ & - & - \\
Static temperature & $\mathrm{K}$ & 223.8 & \pm 1.9 & $\pm 0.8 \%$ & - & - \\
Axial velocity & $\mathrm{m} / \mathrm{s}$ & 2106 & \pm 0.9 & $\pm 0.04 \%$ & - & - \\
Pitot pressure & $\mathrm{kPa}$ & 92.324 & \pm 1.8 & $\pm 1.9 \%$ & - & - \\
\hline \hline
\end{tabular}

the Mach 7 and the test section of the T4 shock tunnel facility. Note that although the actual T4 test section has a square cross-section, it was modelled in the present axisymmetric simulation to have a circular cross-section (with the diameter of the simulated test section matching the height of the actual test section). This was done to avoid performing computationally expensive threedimensional simulations. Since the locations where the Pitot pressure distributions were measured were well upstream of where the expansion of the nozzle outflow reflected off corners in the test section, this simplification was still expected to provide a good conservative estimate of the size of the nozzle core flow. As indicated by the dashed red lines in Figure 8, the core flow diamond of

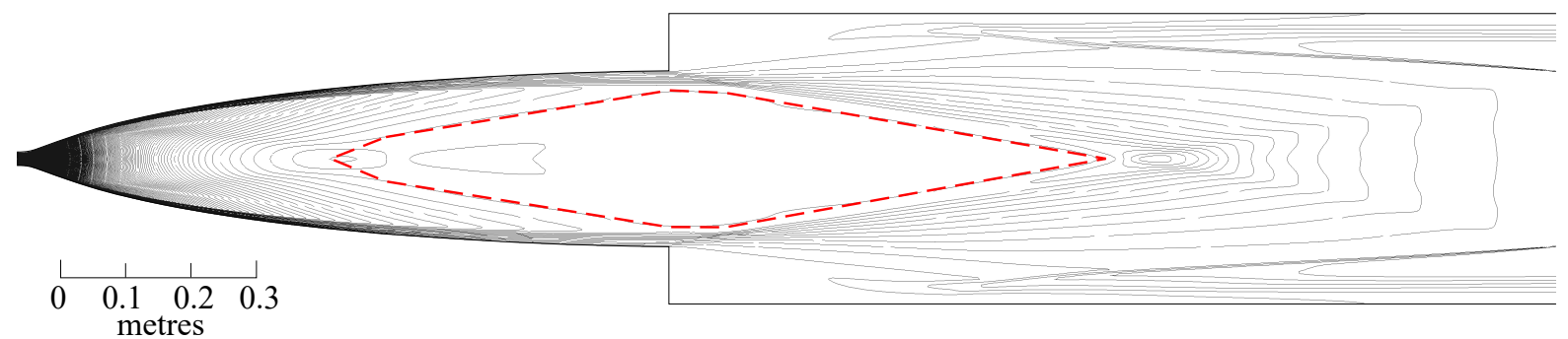

Figure 8. Contours of Pitot pressure for the optimised Mach 7 nozzle. Contours are shown at intervals of 5 kPa.

the optimised nozzle has a maximum axial length of $1.1 \mathrm{~m}$ and a maximum diameter of $0.2 \mathrm{~m}$. 


\section{Experimental validation of design method: Mach 7 nozzle}

To confirm the validity of the proposed design method, a nozzle with the optimised contour was manufactured, and then a survey of the nozzle outflow was conducted with a 33-probe Pitot rake. The Pitot rake is shown in Figure 9. Each Pitot probe was instrumented with a fast-response piezoelectric PCB pressure transducer. The PCB transducers were either model number 112A21 or 112A22. Note also that the sensing face of each PCB transducer was shielded with an approximately $30 \mu \mathrm{m}$-thick cellophane sheet to prevent effects of thermal shocking on the pressure measurements. The Pitot surveys were conducted at three planes located axially downstream of the nozzle exit; at $x=141 \mathrm{~mm}, x=301 \mathrm{~mm}$ and $x=460 \mathrm{~mm}$. Note that although the measured Pitot pressure profiles provide a good indicator of the uniformity and size of the nozzle outflow, measurements of the other flow properties (for example, temperature and flow velocity) will provide more confidence in the experimental validation of the proposed design method.

While the nozzle was designed using a nozzle-supply pressure of $p_{s}$ of $8.32 \mathrm{MPa}$ and a nozzlesupply temperature $T_{s}$ of $2122.7 \mathrm{~K}$, the majority of the validation experiments were conducted at a nominal $p_{s}$ of $19.33 \mathrm{MPa}$ (about 2 times higher than the design $p_{s}$ ) and a nominal $T_{s}$ of of $2371 \mathrm{~K}$ (about 12\% higher than the design $T_{s}$ ). As will be discussed in Section B, these differences in the nozzle-supply conditions did not affect the flow uniformity nor the size of the core flow inferred from the Pitot pressure measurements.

Figure 10 shows an iso-contour plot of Mach numbers in the Mach 7 nozzle and the test section of the T4 shock tunnel facility. Also shown are the three axial locations where the Pitot pressure distributions were surveyed in these validation tests. Note that this CFD simulation was run using the same configuration parameters as those used to generate Figure 8 (the medium grid with 80 radial cells and 600 axial cells in the nozzle), with the exception of two parameters - (1) the inflow total pressure and temperature was set up to match the nominal test values of $19.33 \mathrm{MPa}$ and $2371 \mathrm{~K}$, and (2) the boundary layer was set to transition $50 \mathrm{~mm}$ downstream of the nozzle throat. 


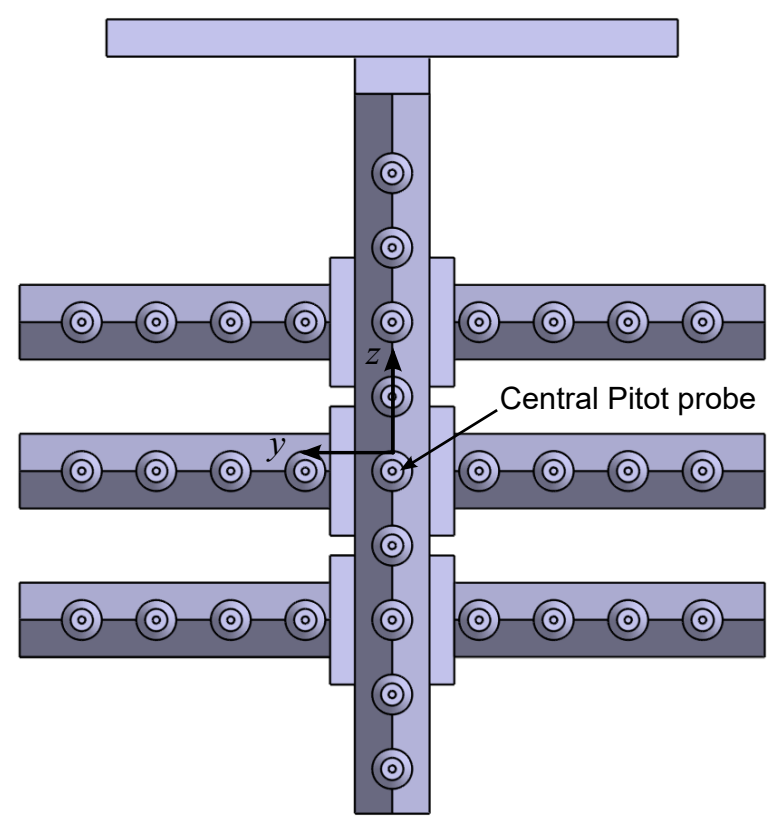

a) Front view of Pitot rake.

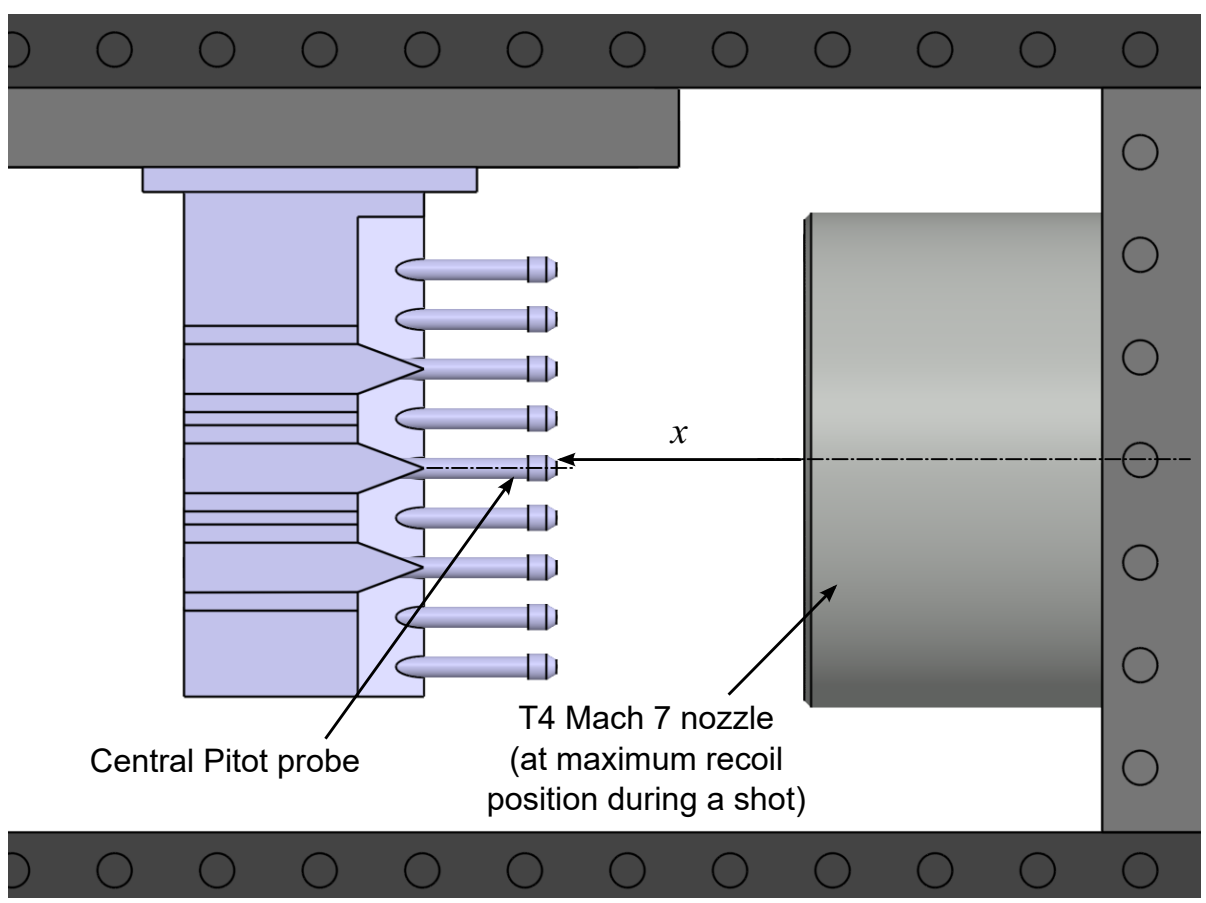

b) Side view of Pitot rake.

Figure 9. Schematic of Pitot rake in T4 test section.

17 of 30 


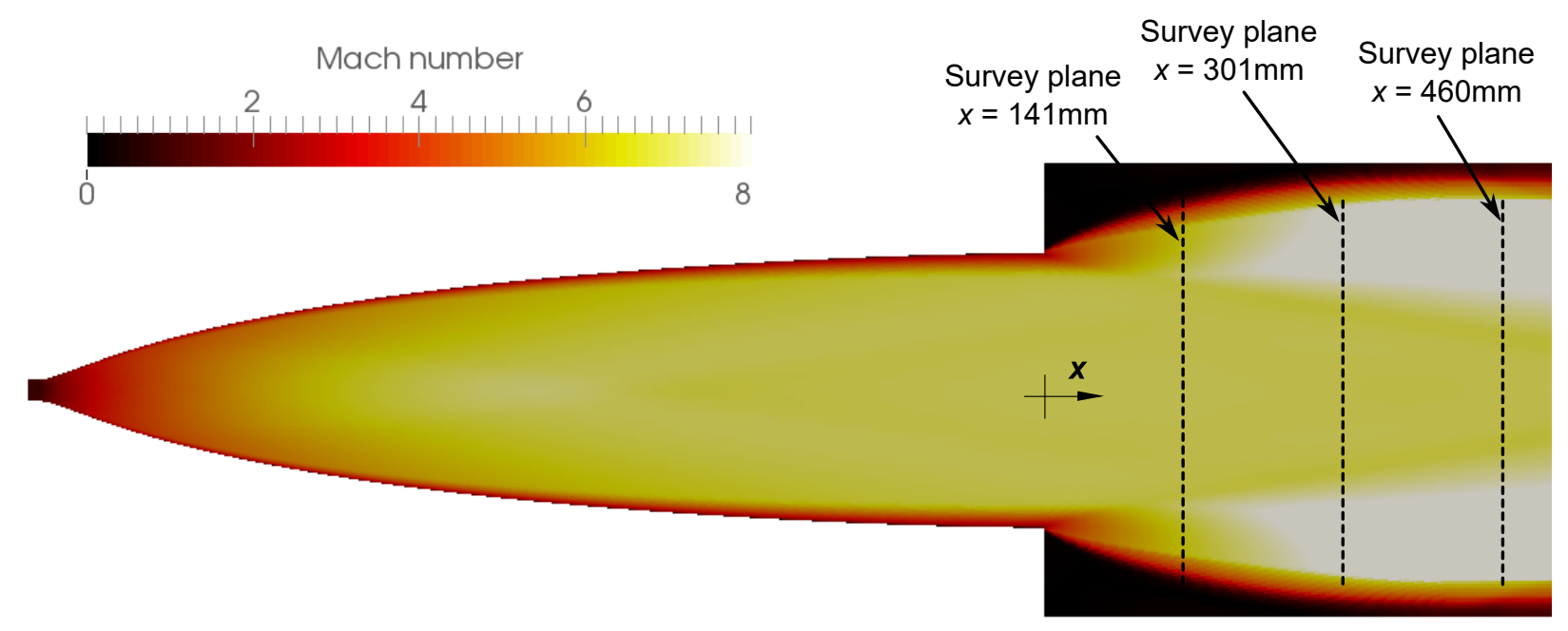

Figure 10. CFD solution showing iso-contours of Mach number.

\section{A. Results at $p_{0}$ and $T_{0}$ of $19.33 \mathrm{MPa}$ and $2371 \mathrm{~K}$}

Comparisons between experimental and numerical Pitot pressure distributions at the three survey planes are shown in Figure 11. For each comparison, the Pitot pressure distributions are presented in the form of a Pitot-to-nozzle-supply pressure ratio. Presenting Pitot pressure measurements in this way minimises the effects of shot-to-shot variations in the freestream conditions which primarily come from variations in the nozzle-supply pressure. The error bars shown for the experimental results were taken to be one standard deviation of the averaged Pitot-to-nozzle-supply pressure ratio within the test duration of $1 \mathrm{~ms}$. It should be noted that the standard deviation of the fluctuations is presented instead of the instrumentation uncertainty of $\pm 6 \%$. The reason for presenting error bars in this manner is because the level of fluctuations in the measurements varied depending on the location of the Pitot probe in the flowfield; hence indicating that the fluctuations were random errors brought about by the flowfield's interaction with the Pitot probe rather than systematic errors in the instrumentation. While random errors can be estimated by taking multiple repeated measurements, the per-shot cost of the T4 shock tunnel test facility restricted the number of shots which could have been conducted to produce a good estimate of the uncertainty.

Note that the radial positions for the experimental data points on these plots were obtained 


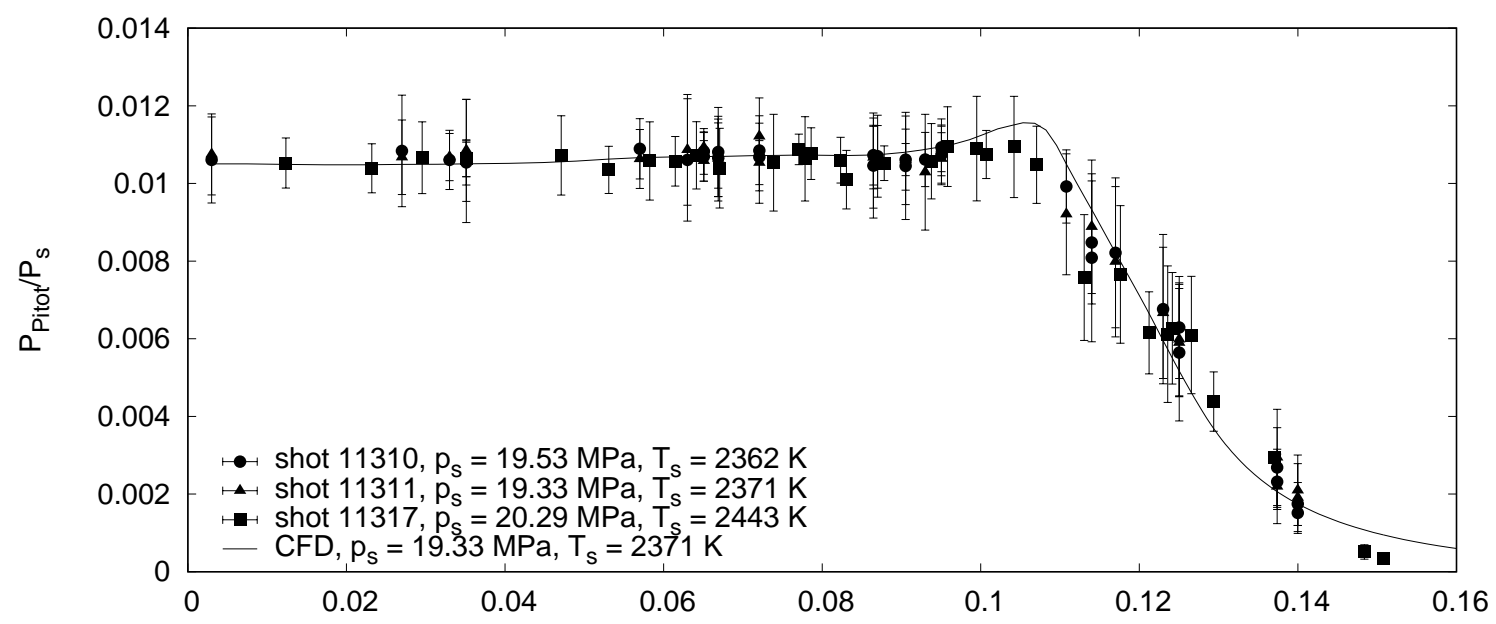

a) $x=141 \mathrm{~mm}$.

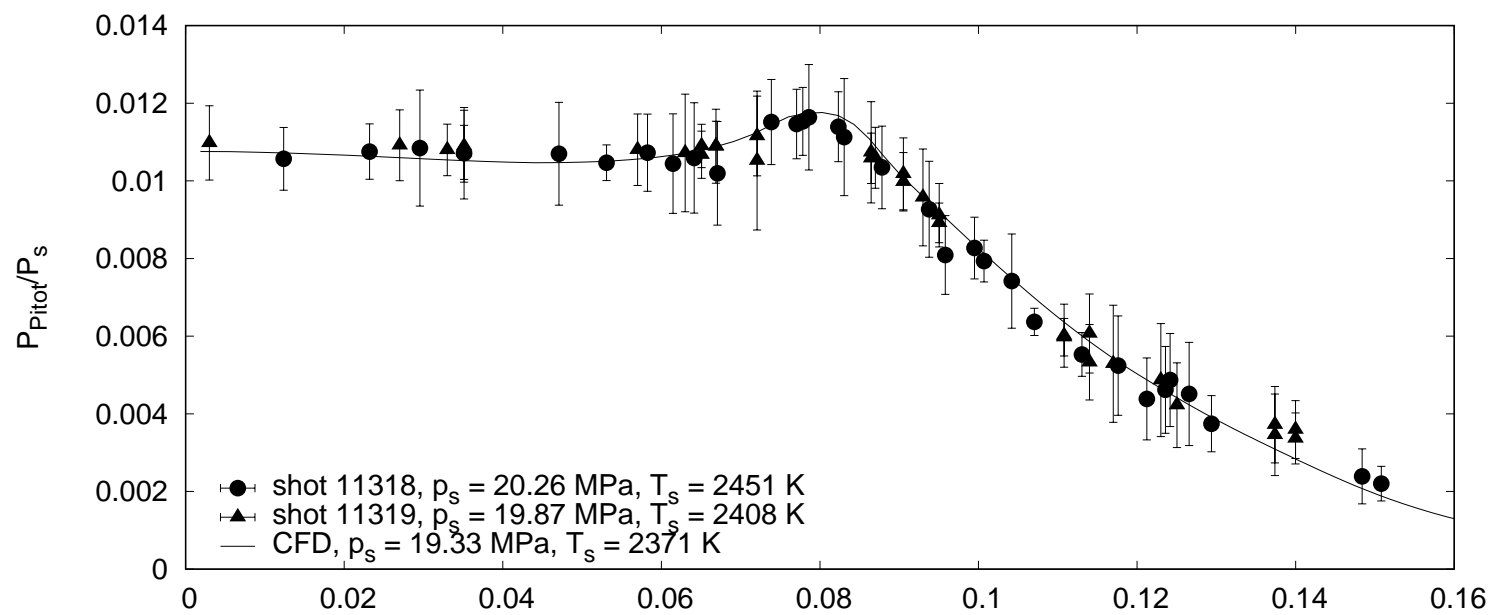

b) $x=300 \mathrm{~mm}$.

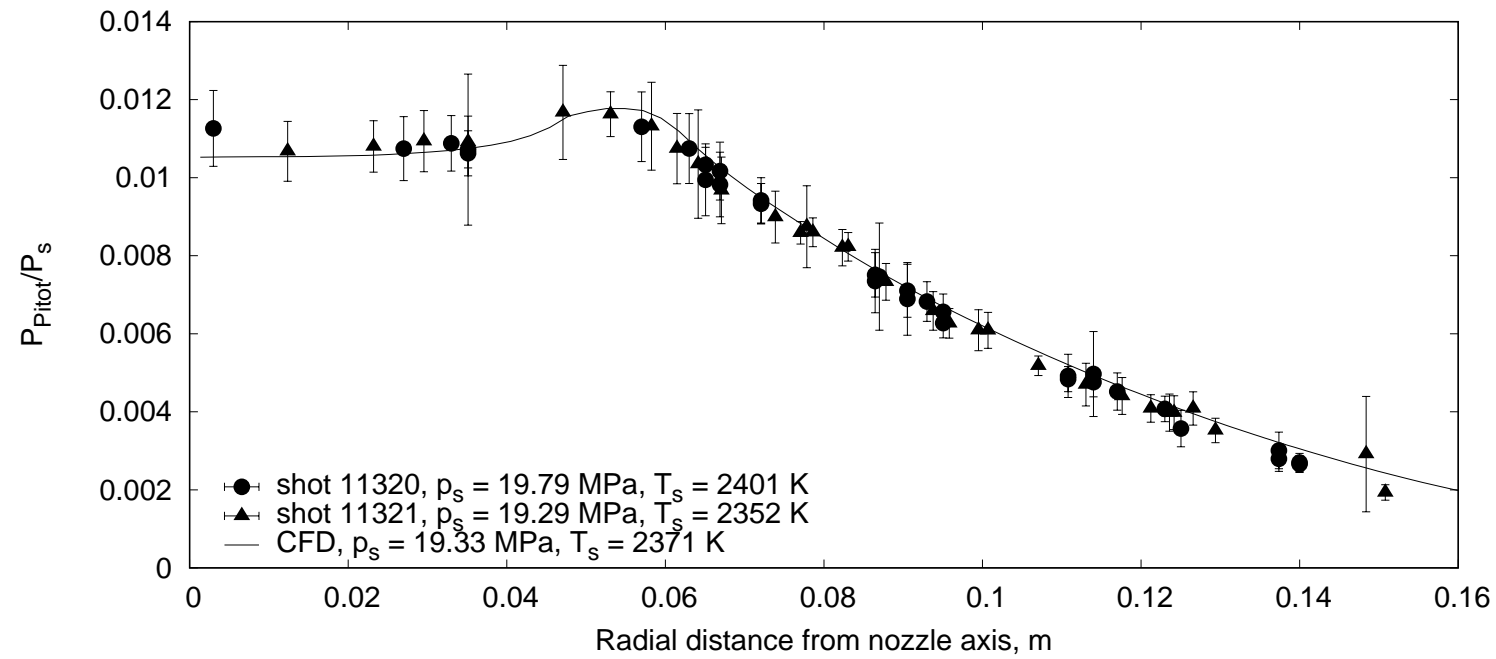

c) $x=460 \mathrm{~mm}$.

Figure 11. Pitot pressure distribution at three axial locations downstream of nozzle-exit. Error bars indicate one standard deviation of the variation during the test time.

19 of 30

American Institute of Aeronautics and Astronautics 
by converting the $y$ and $z$ locations of each Pitot probe to a radial location based on a coordinate system which had its axis aligned with that of the nozzle (see Figure 9 for the coordinate system). For a nozzle outflow that is approximately or truly axisymmetric, the application of this conversion method is appropriate. However, for a nozzle outflow that is not axisymmetric, this method of conversion will result in a large scatter in the Pitot pressure distribution. Figure 11 shows that the scatter in the distribution of averaged Pitot pressure was small compared to the experimental uncertainties, hence indicating that the nozzle outflow was reasonably axisymmetric. Note that flow axisymmetry is to be expected since the design method was implemented axisymmetrically. Rather, the quality of flow axisymmetry indicated in these results is a good indication of the quality of the manufacturing process of the nozzle.

The comparisons in Figure 11 show an excellent agreement between the experimental and numerical Pitot pressure distributions at all three locations downstream of the nozzle exit, hence indicating that the CFD solution is a good approximation of the actual nozzle flowfield. The results also show an excellent level of uniformity in the core flow region of the nozzle flowfield. This, together with the excellent agreement between experiments and numerical simulations, demonstrates the validity of the methodology that was used to design the nozzle flowpath.

\section{B. Sensitivity of flow quality to supply conditions}

The nozzle was also surveyed at three other test conditions to investigate the sensitivity of the nozzle outflow quality to nozzle-supply conditions. The first test condition had a $p_{s}$ of $18.46 \mathrm{MPa}$ and $T_{s}$ of $1707 \mathrm{~K}$, the second had a $p_{s}$ of $13.02 \mathrm{MPa}$ and $T_{s}$ of $1735 \mathrm{~K}$, and the third had a $p_{s}$ of 20.29 $\mathrm{MPa}$ and $T_{s}$ of $2443 \mathrm{~K}$. Figure 12 shows a comparison of the Pitot pressure distributions for the nominal test condition and for these three test conditions. Note that the $x$ positions for the tests at the other three conditions were slightly different to those for the tests at the nominal condition. This difference was brought about by differences in the facility driver conditions for the three test conditions. When run at different driver conditions, the T4 shock tunnel recoils by a different amount, which then sets a different $x$ position.

The results show that despite a $46 \%$ difference in nozzle-supply pressure and a $59 \%$ difference 


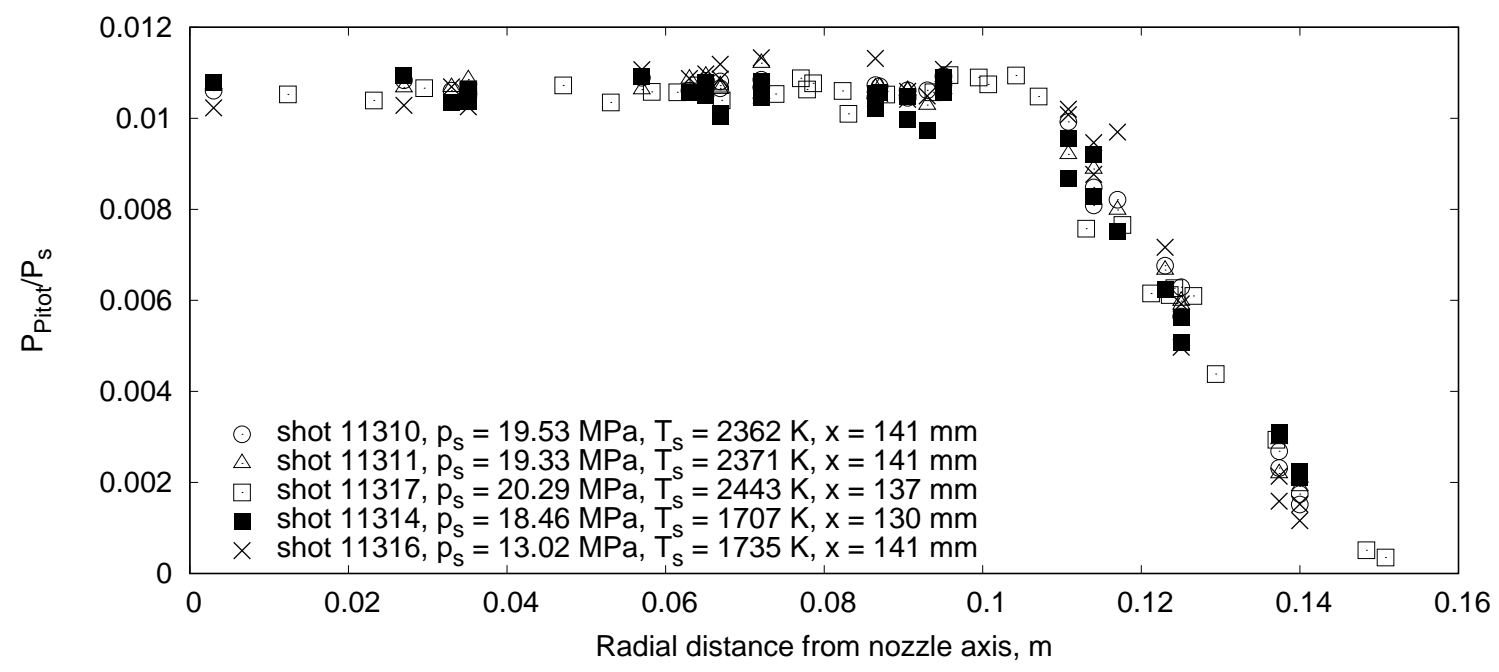

Figure 12. Pitot pressure distribution at $x \approx 140 \mathrm{~mm}$.

in nozzle-supply temperature, there were no discernable differences in the Pitot pressure distributions at $x \approx 140 \mathrm{~mm}$. This is a good indication that the Pitot-to-nozzle-supply pressure ratio was not sensitive to changes in the test conditions (at least for the conditions tested in the current study). These results also indicate that the uniform region of the nozzle flowfield did not change in size when the test condition changed.

To further examine the effects of changing test conditions on the quality of the nozzle outflow, simulations of the nozzle at the four test conditions were conducted. Flow profiles at the nozzle exit for these simulations are shown in Figure 13. Figure 13d shows that, in the core flow region (up to $0.1 \mathrm{~m}$ from the nozzle axis), values for Pitot-to-nozzle-supply pressure ratio varied up to a maximum of 0.001 . This variation was less than the uncertainties in the measurement of Pitot-tonozzle-supply pressure ratio and explains why they were not seen in Figure 12. The Mach number profiles in Figure 13a show that when lower nozzle-supply temperatures (i.e., lower nozzle-supply enthalpies) were used, the exit Mach number in the core flow was higher by $6 \%$. This is to be expected; since the ratio of specific heats is higher at lower nozzle-supply temperatures, the "area ratio - Mach number" equation for ideal gas compressible flows shows that expanding over the same area ratio with a higher ratio of specific heats will result in a higher Mach number. Using a lower nozzle-supply temperature also resulted in a lower static-to-nozzle-supply pressure ratio, as 


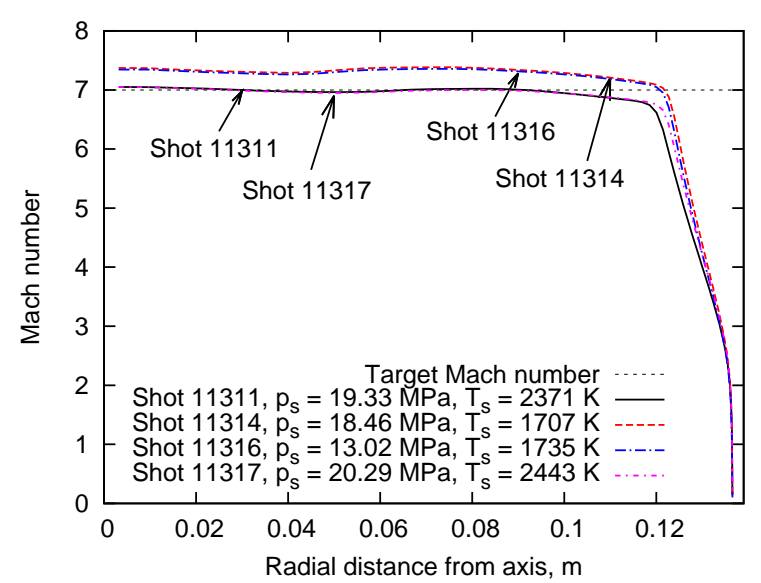

a) Mach number.

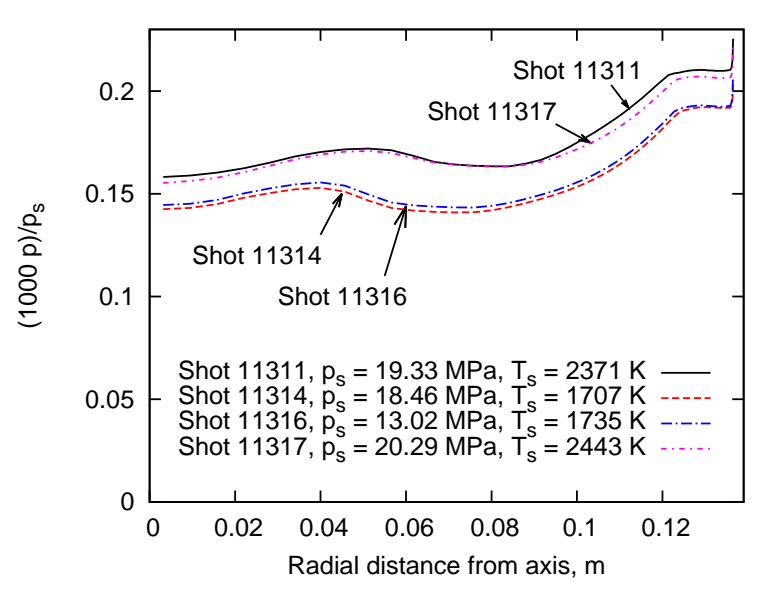

c) Static pressure.

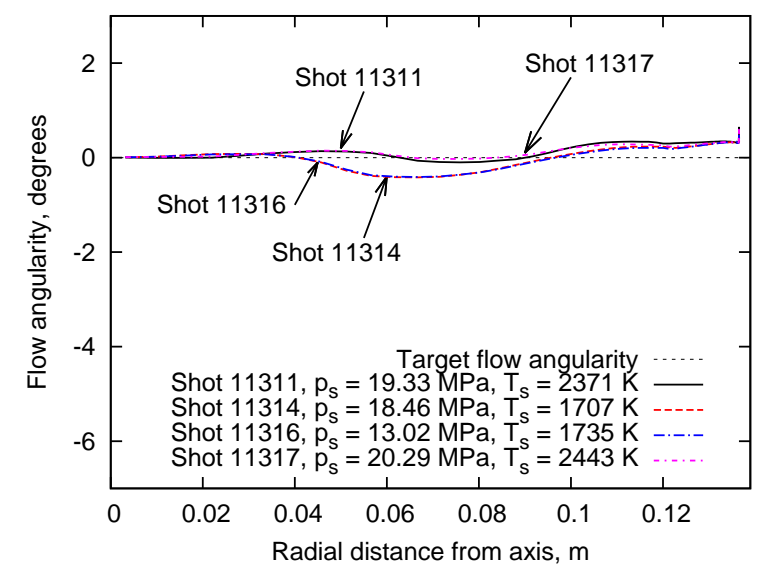

b) Flow angularity.

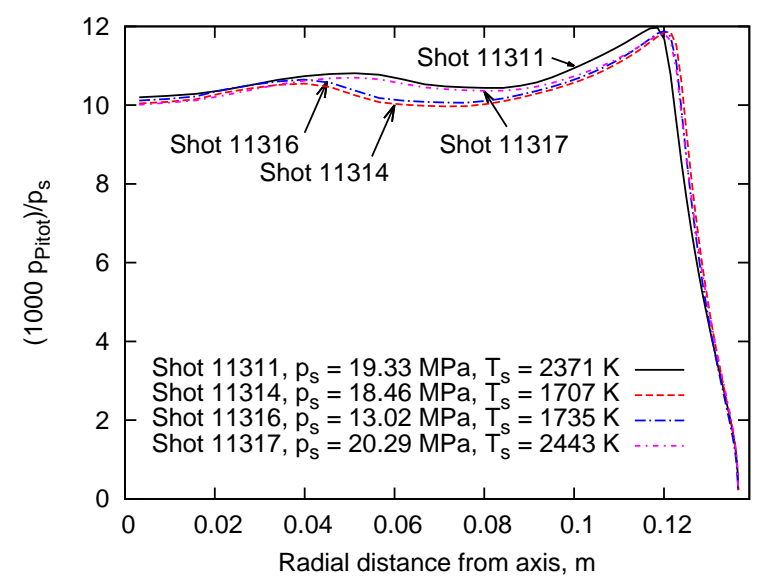

d) Pitot pressure.

Figure 13. Flow profiles at the nozzle exit from simulations of the nozzle at four different test conditions. 
shown in Figure 13c. From Figure 13b, it can be seen that lowering the nozzle-supply temperature increased the maximum flow angularity from $0.05^{\circ}$ to $0.4^{\circ}$. This level of increase in flow angularity is still deemed to be acceptable for the types of tests conducted in hypersonic facilities. From the plots in Figure 13, it can be seen that changing nozzle-supply pressures had significantly less effect on the flow uniformity at nozzle exit than changing nozzle-supply temperatures.

\section{Experimental validation of design method: Mach $4 \& 10$ nozzles}

To further show the robustness of the proposed method for the design of nozzles with uniform outflow, results from Pitot pressure surveys of two other nozzles designed using this method are presented. Note that, unless otherwise specified, the setup (gridding methodology, gas model, boundary and initial conditions) for the CFD simulations for the Mach 4 \& 10 nozzles were the same as that used for the simulation of the Mach 7 nozzle (as described in B).

\section{A. Mach 10 nozzle}

A Mach 10 nozzle was designed for a nozzle-supply pressure and temperature of $50 \mathrm{MPa}$ and $3756 \mathrm{~K}$, and a target nozzle-exit Mach number of 10.0. The optimised nozzle flowpath had an original throat-to-nozzle-exit axial length of $1.9 \mathrm{~m}$, which was considered to be too long for the T4 shock tunnel facility where typical test time durations for a Mach 10-equivalent condition were limited. To ensure that there was sufficient time for the flow to establish in the nozzle, it was thus essential to keep the length of the nozzle to the minimum without sacrificing the quality of the nozzle outflow. Since the Mach 10 nozzle was designed for a higher total enthalpy condition, chemical equilibrium of the flow cannot be assumed. Instead, the simulations were conducted using a thermally perfect mixture of $\mathrm{N}_{2}, \mathrm{O}_{2}, \mathrm{~N}, \mathrm{O}$ and $\mathrm{NO}$ and the reaction scheme of Gupta et al [26]. In addition, the flow was assumed to be thermal equilibrium. For the Mach 10 nozzle, the final truncated axial length was $1.64 \mathrm{~m}$, a throat diameter of $9.52 \mathrm{~mm}$ and an exit diameter of $378.6 \mathrm{~mm}$. CFD simulations of the nozzle showed that the core flow diamond had a maximum diameter of $300 \mathrm{~mm}$ and an axial length of $2.1 \mathrm{~m}$.

Figure 14 shows comparisons between experimental and numerical Pitot pressure distributions 
at two operating conditions $\left(p_{s}=40.1 \mathrm{MPa}, T_{s}=3909 \mathrm{~K}\right.$ and $\left.p_{s}=71.5 \mathrm{MPa}, T_{s}=3837 \mathrm{~K}\right)$ and at two axial planes downstream of the nozzle exit. The numerical results were from simulations conducted assuming that the boundary layer transitioned to turbulence $100 \mathrm{~mm}$ downstream of the nozzle throat. Given the higher total enthalpy for this case, the numerical Pitot pressures were calculated accounting for the change in ratio of specific heats across a normal shock. Note that this method of calculating numerical Pitot pressures is different to the Rayleigh-Pitot method used for the lower total enthalpy cases for the Mach 4 and Mach 7 nozzles.

In the comparisons in Figure 14, a good match between the experiments and the CFD simulations was achieved for both test conditions. For the measurements at $x=165 \mathrm{~mm}$ in Figure $14 \mathrm{~b}$, there appears to be a slight increase in the Pitot pressure profile at a radial distance between $0.06 \mathrm{~m}$ and $0.12 \mathrm{~m}$, which did not appear in the CFD simulations; however, with the levels of uncertainties in the measurements, it is not possible to tell if there was a real mismatch at this location. The results in Figure 14 also show good flow uniformity in the core flow of the Mach 10, thus demonstrating the validity of the proposed nozzle design method.

\section{B. Mach 4 nozzle (known as the T4 Mach 4B nozzle)}

While a smaller and lower Mach number nozzle designed using the MOC/BL method does not suffer from the same issues as a larger and higher Mach number nozzle, it is still interesting to see if the proposed method can be used in the design of a lower Mach number nozzle.

A Mach 4 nozzle was designed for a nozzle-supply pressure and temperature of $8.32 \mathrm{MPa}$ and 2122.7 K, and a target nozzle-exit Mach number of 4.0. In the design process, the flow through the nozzle was assumed to be in thermal equilibrium and the boundary layer in the nozzle was assumed to be laminar based on previous studies [32]. The optimised nozzle contour had a throat diameter of $25 \mathrm{~mm}$ and a exit diameter of $95.576 \mathrm{~mm}$. The maximum slope of the nozzle contour, relative to the nozzle axis, was $12^{\circ}$, and occurred approximately $32 \mathrm{~mm}$ downstream of the nozzle throat. CFD simulations of the nozzle showed that the core flow diamond has a maximum diameter of $92 \mathrm{~mm}$ and an axial length of $318 \mathrm{~mm}$. The CFD simulations also showed that the nozzle-exit flow is extremely uniform - the Mach number varies by $\pm 0.25 \%$, the flow angularity varies by $\pm 0.02^{\circ}$, 


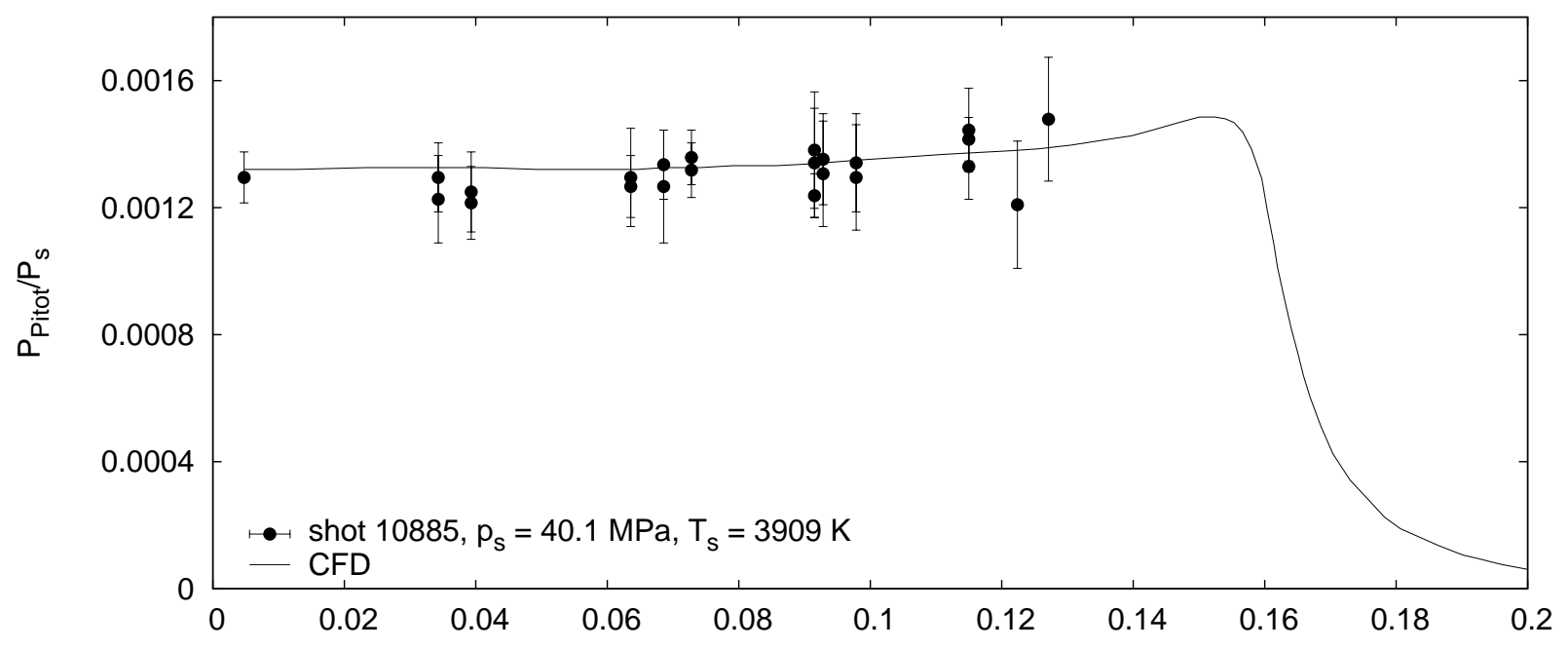

a) $x=135 \mathrm{~mm}$.

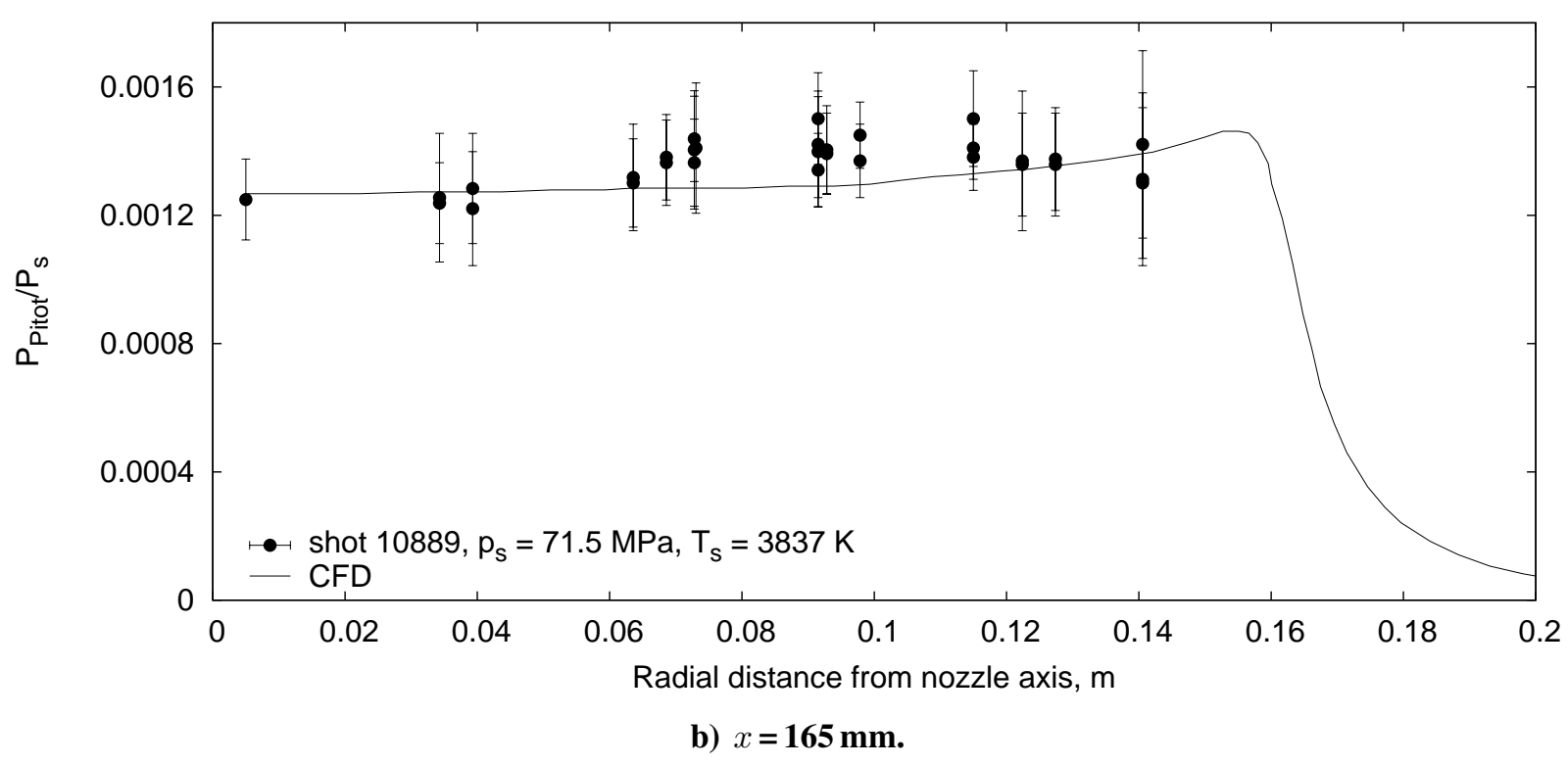

Figure 14. Pitot pressure distribution at two axial locations downstream of the Mach 10 nozzle-exit at two different nozzle-supply conditions. 
and the Pitot and static pressures vary by less than $2 \%$.

Figure 15 shows a comparison between the experimental and numerical Pitot pressure distributions at $115 \mathrm{~mm}$ downstream of the Mach 4 nozzle exit. The numerical results shown were from two simulations - one assuming fully laminar boundary layers in the nozzle, and the other with the boundary layer transitioning to turbulence at $350 \mathrm{~mm}$ downstream of the nozzle throat. The

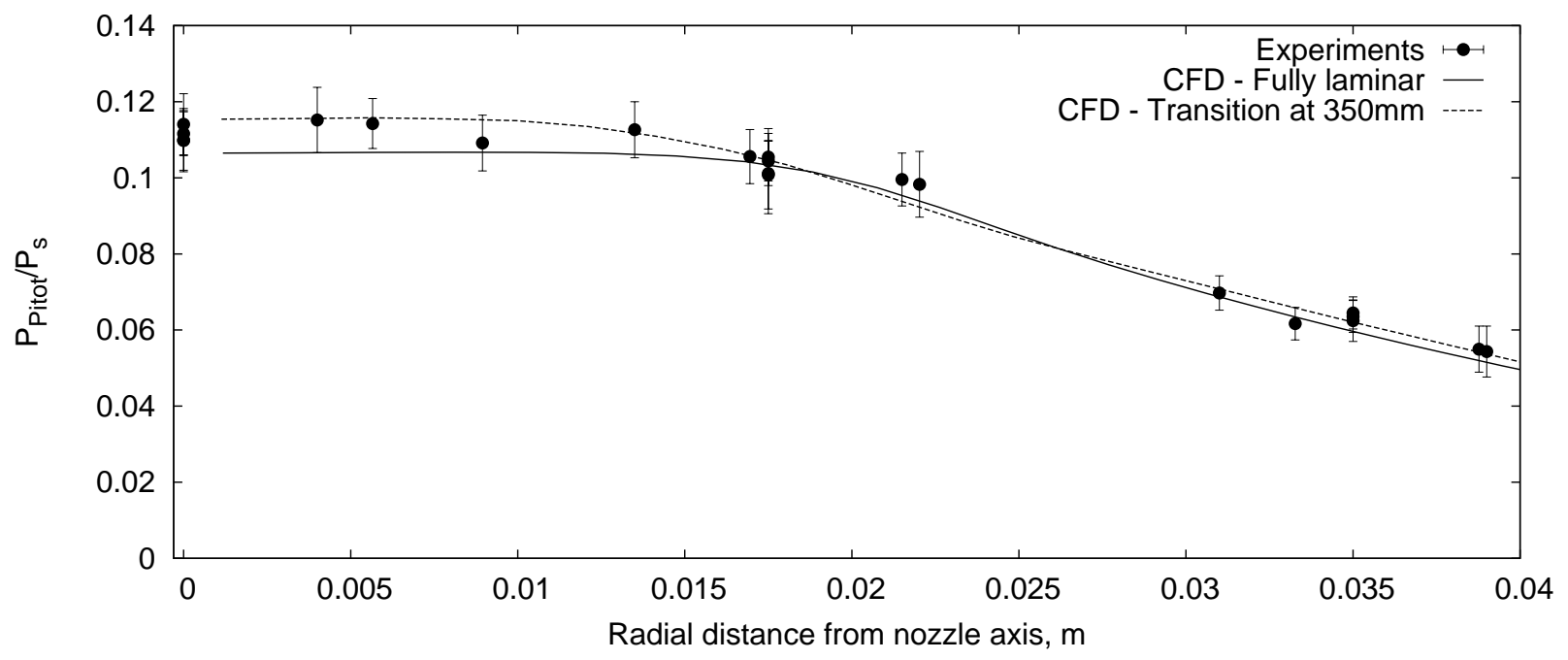

Figure 15. Experimental and numerical Pitot pressure distribution at $115 \mathrm{~mm}$ downstream of the Mach 4 nozzle-exit.

comparison shows that the earlier assumption that the boundary layer is entirely laminar in the nozzle is incorrect. The simulation with the boundary layer transitioning at $350 \mathrm{~mm}$ gives a better match to the experiments, thus indicating that the boundary layer in the Mach 4 nozzle transitions to turbulence at some point in the nozzle. Despite this, the core flow produced by this nozzle still exhibits good flow uniformity, thus providing yet another demonstration of the validity of the proposed nozzle design method.

\section{Conclusion}

The proposed method was applied in the design of three nozzles for the T4 shock tunnel facility at the University of Queensland; namely a Mach 4, Mach 7 and Mach 10 nozzle. Excellent agreements between the experimental and numerical Pitot pressure distributions were achieved for all three new nozzles, hence demonstrating the validity of the proposed nozzle design method. 
Numerical simulations of the flow in these nozzles showed excellent flow uniformity in the core flow; typical Mach number variations were less than $0.5 \%$, flow angularity variations were less than $0.05^{\circ}$, static temperature and flow velocity variations were less than $1 \%$, and Pitot and static pressures variations were less than $2 \%$. The experimentally-measured Pitot pressure distributions showed that there were good levels of uniformity in the core flow regions of all three nozzles. Additional tests for the Mach 7 nozzle indicated that the distribution of Pitot-to-nozzle-supply pressure ratio and the size of the uniform region of the nozzle flowfield were not significantly sensitive to changes in the nozzle-supply conditions.

Several recommendations for future work are suggested as a result of this investigation. Firstly, more sensitive and non-intrusive flow diagnostics can be used to measure the other nozzle outflow properties (for example, temperature and flow velocity). This will provide even more confidence in the experimental validation of the proposed design method. Secondly, the objective function can be adjusted to provide uniformity in not only Mach number and flow angularity, but also other flow parameters like static pressure and temperature. Lastly, in the definition of the Bèzier control points for the optimisation problem, it is suggested that the radial positions of the last two Bèzier control points be the same as each other, and that the values are held constant during the optimisation to ensure that the very last portion of the nozzle contour is always parallel to the axis at the nozzle exit.

\section{Acknowledgments}

The authors would like to acknowledge the efforts of the UQ faculty workshop technicians Robert McGregor, Gary Manning, Jason Herriot, Christopher Lloyd and Keith Hitchcock for the manufacture of the new nozzles. The authors would also like to acknowledge Tristan Vanyai, Kevin Basore, James Barth and Daniel Oberg for operating the T4 shock tunnel facility for the nozzle validation tests. 


\section{References}

[1] Murthy, S. N. B. and Curran, E. T., editors, Scramjet Propulsion, American Institute of Aeronautics and Astronautics, New York, USA, 2001.

doi: $10.2514 / 4.866609$.

[2] Pope, A. and Goin, K. L., High-Speed Wind Tunnel Testing, John Wiley \& Sons, Inc., New York, USA, 1965.

[3] Stalker, R. J., Paull, A., Mee, D. J., Morgan, R. G., and Jacobs, P. A., "Scramjets and Shock tunnels The Queensland Experience," Progress in Aerospace Sciences, Vol. 41, No. 6, 2005, pp. 471-513. doi: 10.1016/j.paerosci.2005.08.002.

[4] Hannemann, K., Itoh, K., Mee, D. J., and Hornung, H. G., Experimental Methods of Shock Wave Research, chap. Free Piston Shock Tunnels HEG, HIEST, T4 and T5, Springer, New York, USA, 2016, pp. 181-264.

doi: 10.1007/978-3-319-23745-9.

[5] Prandtl, L. and Busemann, A., Naherungsverfahren zur Zeichnerischen Ermittlung von Ebenen Strömungen mit Übershllgeschwindigkeit, Füssli Verlag, 1929.

[6] Sivells, J. C., "Aerodynamic Design of Axisymmetric Hypersonic Wind-Tunnel Nozzles," Journal of Spacecraft and Rockets, Vol. 11, No. 11, 1970, pp. 1292-1299.

doi: $10.2514 / 3.30160$.

[7] Candler, G. V. and Perkins, J. N., "Effects of Vibrational Nonequilibrium on Axisymmetric Hypersonic Nozzle Design," 29th AIAA Aerospace Sciences Meeting and Exhibit, No. AIAA 91-0297, American Institute of Aeronautics and Astronautics Inc., Reno, Nevada, USA, 7-10 January 1991. doi: 10.2514/6.1991-297.

[8] Benton, J. R., Edwards, A. C., and Perkins, J. N., "Limitations of the Method of Characteristics When Applied to Axisymmetric Hypersonic Nozzle Design," 28th AIAA Aerospace Sciences Meeting, No. AIAA 90-0192, American Institute of Aeronautics and Astronautics Inc., Reno, Nevada, USA, 8-11 January 1990.

doi: $10.2514 / 6.1990-192$.

[9] Craddock, C. S., "Design of the Axisymmetric HyShot Nozzle for T4," Department of Mechanical Engineering Report 2/00, The University of Queensland, 2000.

[10] Korte, J. J., "Aerodynamic Design of Axisymmetric Hypersonic Wind-Tunnel Nozzles Using a LeastSquares/Parabolized Navier-Stokes Procedure," Journal of Spacecraft and Rockets, Vol. 29, No. 5, 1992, pp. 685-691.

doi: $10.2514 / 3.11511$.

[11] Korte, J. J., Kumar, A., Singh, D. J., and White, J. A., "CAN-DO, CFD-based Aerodynamic Nozzle Design and Optimization Program for Supersonic/Hypersonic Wind Tunnels," 17th AIAA Aerospace Ground Testing Conference, No. AIAA 92-4009, American Institute of Aeronautics and Astronautics Inc., Nashville, Tennessee, USA, 6-8 July 1992.

doi: $10.2514 / 6.1992-4009$.

[12] Korte, J. J. and Hodge, J. S., "Flow Quality of Hypersonic Wind-Tliimel Nozzles Designed Using Computational Fluid Dynamics," Journal of Spacecraft and Rockets, Vol. 32, No. 4, 1995, pp. 569580.

doi: $10.2514 / 3.26655$. 
[13] Shope, F. L., "Contour Design Techniques for Super/Hypersonic Wind Tunnel Nozzles," 24th AIAA Applied Aerodynamics Conference, No. AIAA 2006-3665, American Institute of Aeronautics and Astronautics, American Institute of Aeronautics and Astronautics, San Francisco, California, USA, 5 - 8 June 2006.

doi: $10.2514 / 6.2006-3665$.

[14] Keeling, S. L., "A Strategy for the Optimal Design of Nozzle Contours," 28th AIAA Thermophysics Conference, No. AIAA 93-2720, American Institute of Aeronautics and Astronautics Inc., Orlando, Florida, USA, 6-9 July 1993.

doi: $10.2514 / 6.1993-2720$.

[15] Tolle, R., "A New Optimum Design Code for Hypersonic Nozzles, Utilizing Response Surface Methodology," 35th AIAA Aerospace Sciences Meeting and Exhibit, No. AIAA 97-0519, American Institute of Aeronautics and Astronautics Inc., Reno, Nevada, USA, 6-10 January 1997. doi: 10.2514/6.1997-519.

[16] Gollan, R. J. and Jacobs, P. A., "About the Formulation, Verification and Validation of the Hypersonic Flow Solver Eilmer," International Journal for Numerical Methods in Fluids, Vol. 73, No. 1, 2013, pp. 19-57.

doi: 10.1002/fld.3790.

[17] Nelder, J. A. and Mead, R., “A Simplex Method for Function Minimization,” Computer Journal, Vol. 7, 1965, pp. 338-345.

[18] Chan, W. Y. K., Jacobs, P. A., and Mee, D. J., "Suitability of the $k$ - $\omega$ Turbulence Model for Scramjet Flowfield Simulations," International Journal for Numerical Methods in Fluids, Vol. 70, No. 4, 2012, pp. 493-514. doi: 10.1002/fld.2699.

[19] Kirchhartz, R. M., Mee, D. J., Stalker, R. J., Jacobs, P. A., and Smart, M. K., "Supersonic BoundaryLayer Combustion: Effects of Upstream Entropy and Shear-Layer Thickness," Journal of Propulsion and Power, Vol. 26, No. 1, 2010, pp. 57-66.

doi: $10.2514 / 1.44485$.

[20] Tanimizu, K., Mee, D. J., Stalker, R. J., and Jacobs, P. A., "Drag Force on Quasi-Axisymmetric Scramjets at Various Flight Mach Numbers: Theory and Experiment," Shock Waves, Vol. 19, No. 2, 2009, pp. 83-93.

doi: 10.1007/s00193-009-0194-x.

[21] O’Byrne, S. and Wittig, S., "Measurement of Hypersonic Inlet Flow using Diode Laser Absorption Spectroscopy," Proceedings of the 8th Australian Space Science Conference, National Space Society of Australia Ltd, Canberra, Australia, 29 September - 1 October 2008, pp. 68-75.

[22] Kulkarni, V., Kulkarni, P. S., and Reddy, K. P. J., "Drag Reduction by a Forward Facing Aerospike for a Large Angle Blunt Cone in High Enthalpy Flows," 26th International Symposium on Shock Waves, Vol. 1, Springer-Verlag, Berlin, Heidelberg, Gottingen, Germany, 15-20 July 2007, pp. 565-570.

[23] McGilvray, M., Austin, J. M., Sharma, M., Jacobs, P. A., and Morgan, R. G., "Diagnostic Modelling of an Expansion Tube Operating Condition," Shock Waves, Vol. 19, No. 1, 2009, pp. 59-66.

doi: 10.1007/s00193-009-0187-9.

[24] Wheatley, V., Chiu, H. S., Jacobs, P. A., Macrossan, M. N., Mee, D. J., and Morgan, R. G., "Rarefied, Superorbital Flows in an Expansion Tube," International Journal of Numerical Methods for Heat \& 
Fluid Flow, Vol. 14, No. 4, 2004, pp. 512-537.

doi: 10.1108/09615530410532277.

[25] Doherty, L., Chan, W. Y. K., Jacobs, P. A., Zander, F., Gollan, R. J., and Kirchhartz, R. M., "NENZFr: Non-Equilibrium NozZle Flow, Reloaded. A User Guide.” Department of Mechanical Engineering Report 2012/08, The University of Queensland, 2012.

[26] Gupta, R. N., Yos, J. M., Thompson, R. A., and Lee, K. P., "A Review of Reaction Rates and Thermodynamic and Transport Properties for an 11-Species Air Model for Chemical and Thermal Nonequilibrium Calculations to 30000 K," Tech. Rep. NASA RP 1232, NASA, 1990.

[27] Hannemann, K., Schramm, J. M., Wagner, A., Karl, S., and Hannemann, V., "A Closely Coupled Experimental and Numerical Approach for Hypersonic and High Enthalpy Flow Investigations Utilising the HEG Shock Tunnel and the DLR TAU Code," Tech. Rep. RTO-EN-AVT-186, North Atlantic Treaty Organization, 2010.

[28] Wilcox, D. C., Turbulence Modelling for CFD, DCW Industries, Inc, California, USA, 3rd ed., November 2006.

[29] Chan, W. Y. K., Smart, M. K., and Jacobs, P. A., "Flowpath Design of an Axisymmetric Mach 7.0 Nozzle for T4," Department of Mechanical Engineering Report 2013/02 (also UQ HIFiRE8 Technical Report Number 2013/01), The University of Queensland, 2013.

[30] Craddock, C. S., Computational Optimization of Scramjets and Shock Tunnel Nozzles, $\mathrm{PhD}$ thesis, The University of Queensland, Queensland, Australia, 1999.

[31] Roache, P. J., “A Method for Uniform Reporting of Grid Refinement Studies," Journal of Fluids Engineering, Vol. 116, No. 3, 1994, pp. 405413.

doi: 10.1115/1.2910291.

[32] Kirchhartz, R. M., Upstream Wall Layer Effects on Drag Reduction with Boundary Layer Combustion, $\mathrm{PhD}$ thesis, The University of Queensland, Queensland, Australia, 2010. 